\title{
Specification and function of hemogenic endothelium during embryogenesis
}

\author{
Emily Gritz $^{1,2} \cdot$ Karen K. Hirschi ${ }^{1}$
}

Received: 20 August 2015/Revised: 16 December 2015/Accepted: 7 January 2016/Published online: 5 February 2016

(C) The Author(s) 2016. This article is published with open access at Springerlink.com

\begin{abstract}
Hemogenic endothelium is a specialized subset of developing vascular endothelium that acquires hematopoietic potential and can give rise to multilineage hematopoietic stem and progenitor cells during a narrow developmental window in tissues such as the extraembryonic yolk sac and embryonic aorta-gonad-mesonephros. Herein, we review current knowledge about the historical and developmental origins of hemogenic endothelium, the molecular events that govern hemogenic specification of vascular endothelial cells, the generation of multilineage hematopoietic stem and progenitor cells from hemogenic endothelium, and the potential for translational applications of knowledge gained from further study of these processes.
\end{abstract}

keywords Embryogenesis .

Developmental hematopoiesis - Hemogenic endothelium · Endothelial to hematopoietic transition

Karen K. Hirschi

karen.hirschi@yale.edu

1 Departments of Medicine, Genetics and Biomedical Engineering, Yale Cardiovascular Research Center, Vascular Biology and Therapeutics Program, and Yale Stem Cell Center, Yale University School of Medicine, 300 George St., New Haven, CT 06511, USA

2 Department of Pediatrics, Section of Neonatal-Perinatal Medicine, Yale University School of Medicine, 333 Cedar St., New Haven, CT 06511, USA

\section{Introduction}

Normal embryogenesis is predicated upon the development of a functioning cardiovascular system early in gestationdisruptions in this lead to vascular, cardiac, hematologic disease, and in extreme cases embryonic lethality. As the primitive vasculature expands throughout early development, it remodels and specializes to fulfill the critical metabolic demands of the tissues it supplies [1]. As part of this remodeling, endothelial cells lining the cardiovascular system subspecialize to arterial, venous, lymphatic, and hemogenic fates via a complex network of intersecting molecular pathways. The mechanisms underlying normal vascular development remain as yet incompletely defined, and a greater understanding of these processes will enhance our understanding of certain pathologic states related to the vascular system and how they might be treated.

Hemogenic endothelium is a small, specialized subset of vascular endothelium that acquires hematopoietic potential and can give rise to multilineage hematopoietic stem and progenitor cells (HSPC) within a narrow developmental window within distinct tissues [1]. Work in the last decade has begun to clarify the complex signals that lead to acquisition of this blood-forming potential. Our understanding of the events that lead to hemogenic specification of endothelial cells from vascular endothelium, as well as the events that lead to generation of HSPC from hemogenic endothelium is still in its infancy. This review will outline current knowledge about the historical and developmental origins of hemogenic endothelium, the molecular events that govern hemogenic specification of vascular endothelial cells, the generation of multilineage HSPC from hemogenic endothelium, and the potential for clinical/translational applications of knowledge gained from further study of these processes. 


\section{Developmental and historical origins of hemogenic endothelium}

\section{Primitive hematopoiesis}

Hematopoiesis occurs in two waves during embryonic development-the primitive (precirculation) wave and definitive wave. The first blood and endothelial cells are derived from the extraembryonic mesoderm beginning around embryonic day (E) 7.0 [2]; whether they are derived from a common bipotent progenitor (hemangioblast), or are independently fated, remains a subject of debate, as discussed later in this review. Primitive hematopoiesis is marked by the brief emergence of mostly nucleated erythroid progenitors, as well as macrophage progenitors [3], that are generated in parallel with endothelial cells. These primitive erythroid cells are functionally and morphologically distinct from later erythroid progenitors in that they are large, nucleated, express embryonic globins, and are exclusively detected in the extra-embyonic yolk sac during a narrow ( $\sim 48 \mathrm{~h})$ window before they disappear [3]. Other precirculation extra-embryonic sources of pro-definitive erythroid and myeloid progenitor cells later emerge between E7.5 and E8.0 and include the allantois [4, 5] and para-aortic splanchnopleura (pSP) [6, 7]. These early cells are of great importance to the developing embryo as they sustain embryonic survival until the definitive hematopoietic system is established, and they form structures referred to as "blood islands" around E7.5 [8], in which the cells in the interior give rise to nucleated erythroid and myeloid cells and those on the periphery become lumenized endothelial cells [1]. Blood islands then coalesce to form vascular channels and a plexus network throughout the yolk sac, which conducts oscillatory plasma flow driven by the developing heart tube [9]. By E8.25, a second wave of erythromyeloid progenitor (EMP) cells are generated which also give rise to tissue macrophages that persist into adulthood [10-12]. Following the onset of plasma flow, the immature progenitor cells join the plasma circulation $[3,13]$.

\section{Definitive hematopoiesis}

Definitive hematopoiesis is the second phase of blood production beginning with production of erythroid and myeloid progenitors that is then followed by generation of long-term repopulating hematopoietic stem cells (HSC) capable of colonizing hematopoietic organs and giving rise to all differentiated blood lineages [14, 15]. Definitive hematopoiesis coincides with the onset of pulsatile blood flow due to coordinated cardiac contraction beginning around E8.25, as the first wave of extra-embryonic primitive erythroid progenitors previously described decrease in number and the previously described second yolk sac wave of erythroid and myeloid cells are generated and enter the plasma circulation $[3,14,16]$. Generation of hematopoietic progenitors then begins in the placenta between E9.0 and 9.5 [17-20]. In the murine embryo proper, definitive hematopoiesis occurs later, within the aorta-gonad-mesonephros (AGM) region peaking at E10.5 [21-23] and is marked by the generation of both progenitor cells, as well as HSC. These AGM and yolk-sac-derived hematopoietic stem and progenitor cells are thought to migrate to, and colonize other sites of definitive hematopoiesis, most notably the fetal liver by E11.0-E12.0 [2426] and the bone marrow at E16.5 [27], and contribute to the adult HSC pool. While it is clear that progenitor cells emerge from the yolk sac and placental tissues during definitive hematopoiesis, it remains debated whether or not the placenta and yolk sac actually generate HSC de-novoalthough it has been shown that the number of HSC colonizing the fetal liver is greater than what can be accounted for by the AGM alone [26]. This suggests that additional sources of HSC, such as the placenta and yolk sac, may exist and contribute to the HSC pool used by the liver for self-expansion [14, 18, 26, 28]. It also remains unclear whether there exists de-novo generation of HSC within fetal liver, fetal bone marrow or postnatal tissues, or if HSC are merely replenished via self-renewal of yolk sac- and AGM-derived cells [29].

While it has been demonstrated that the yolk sac and AGM are sites of definitive hematopoiesis, the cellular origins of the HSPC within these tissues is still under investigation, and may be different in distinct species. Nonetheless, it is generally thought that murine definitive HSPC are derived from a small subset of vascular endothelium that acquires hemogenic potential, so-called hemogenic endothelium. Interestingly, hematopoietic cells produced by hemogenic endothelial cells have different functional characteristics depending on their site of origin [29]. That is, yolk sac hemogenic endothelial cells give rise to multilineage hematopoietic progenitors that cannot repopulate neonatal or adult bone marrow long-term in vivo [7], and are therefore referred to as multilineage progenitors. In contrast, AGM-derived hematopoietic cells are capable of rescuing irradiated neonatal and adult recipients [30]; thus, these cells are considered definitive HSC. This raises the possibility that not all hemogenic endothelial cells are created equally, or that their anatomic niche influences their function and progeny, in a manner dependent on the developmental timing of their emergence and/or the cellular and extracellular composition of their microenvironment [29]. 


\section{Concept evolution of hemogenic endothelium}

To best understand the significance of hemogenic endothelial cells in embryonic hematopoiesis, it is useful to consider the evolution of the concept of their existence and function over the course of the last century. Insights gained during their discovery, identification and characterization have helped intertwine the fields of hematopoietic stem cell biology and vascular biology. The concept of hemogenic endothelium dates back in the scientific literature to the late 19 th century. Beginning in 1899 , several anatomists observed an association of blood forming cells with developing vascular structures across a wide variety of mammalian species including the bat (1899), chick (1907), rabbit (1909), human (1912), pig (1916), and mongoose (1917) [15]. In 1917, anatomist Florence Sabin directly observed in chick embryo studies that "red blood-corpuscles can be seen to grow from the endothelial lining of blood-vessels" [31]. These blood cells were then noted to bud off from vascular endothelial cells into plasma flowing through primitive vascular plexus of the developing chick.

In the 1930s, Murray re-branded Sabin's "angioblast" as a "hemangioblast" or a subset of mesenchymallyderived primitive endothelium that transiently acquires blood-forming potential [32]. Over the next several decades, however, this concept of the hemangioblast and the questions surrounding an association between vascular endothelium and blood formation went largely unaddressed. In the 1960s, Moore and Owen suggested that all embryonic hematopoiesis occurred in the extra-embryonic yolk sac, and that intra-embryonic blood in later stages of development was a result of migration of yolk sac derived hematopoietic progenitors [15]. This concept of exclusively extra-embryonic hematopoiesis was refuted by Dieterlen-Lièvre and coworkers in 1975 when they demonstrated intraembryonic aortic hemogenesis in quailchick embryo grafting experiments and renewed interest in the origin of hematopoietic stem and progenitor cells in the developing embryo $[15,33]$.

\section{The hemangioblast}

Over the next two decades, several groups corroborated the work of Dieterlen-Lièvre and coworkers by demonstrating the presence of hematopoietic stem and progenitor cells in the ventral aspect of the developing dorsal aorta prior to hepatic colonization, and demonstrated that these cell clusters are necessary for the establishment of definitive hematopoiesis $[6,15,23,24,34,35]$. This confirmed association of hematopoietic cells with vascular endothelium brought into question the developmental relationship between hematopoietic cells and vascular endotheliumwere they two independent lineages derived from discrete progenitor cell types or did they have a common mesodermally-derived bipotent cell progenitor, the so-called hemangioblast, that transiently gives rise to vascular endothelial and blood cells? [29]. Indeed, endothelial and hematopoietic lineages have been shown to share many common surface markers and transcription factors that are implicated throughout their differentiation. These include mesodermal markers Brachyury (Bry), bone morphogenic protein 4 (BMP4), and vascular endothelial growth factor 2 (VEGFR2 or Flk-1) [36]; shared markers CD34, VE-cadherin, and $\mathrm{CD} 31$; and common transcription factors RUNX1 and GATA binding protein 2 (GATA2) [37], lending credibility to the hemangioblast concept. However, to date, there is a lack of convincing evidence to suggest that such an exclusively bipotent mesodermal progenitor exists [29].

The bipotent hemangioblast has been described as coexpressing mesodermal marker Bry and Flk-1, but Bry+Flk-1+ cells have, in fact, been demonstrated to give rise to cardiac, skeletal, and vascular smooth muscle, as well as endothelial cells and blood cells [38, 39]. PadrónBarthe and coworkers demonstrated by in vivo clonal analysis of murine embryos that the earliest blood and endothelial lineages do not arise from a primitive streakderived bipotential precursor, but that these lineages are derived from independent epiblast populations [40]. These results are consistent with previous mesodermal grafting studies that also suggest endothelial and blood cell lineages are independently fated during primitive hematopoiesis [41]. It remains possible that there may exist a bipotent mesodermal progenitor giving rise to exclusively endothelial and blood cells, but this has not been definitively demonstrated to date [29]. A middle ground to the hemangioblast debate was proposed by Lancrin and coworkers, wherein the mesodermally-derived hemangioblast gives rise to an endothelial intermediate (hemogenic endothelium) that then gives rise to HSPC [42].

\section{Hemogenic endothelium}

Despite the uncertainty of the existence of hemangioblasts during primitive hematopoiesis, several landmark studies over the last two decades have provided strong evidence that during definitive hematopoiesis in vertebrates, multipotent HSPC arise directly from transiently specialized vascular endothelium (hemogenic endothelium) within the developing AGM between E10.0 and E11.5, prior to appearance in other intra-embryonic hematopoietic organs $[6,23,24,34,35]$.

The aforementioned early observations of blood cells budding from vascular endothelium have been corroborated by dye-labeled fate tracing approaches that 
demonstrate across multiple animal models that dye-tagged vascular endothelium in the dorsal aorta gives rise to dyetagged circulating blood cells $[43,44]$. Subsequent in vivo fate tracing studies in murine embryos has further demonstrated emergence of HSC from endothelium from VE-cad+ cells in the dorsal aorta that go on to colonize intra-embryonic hematopoietic sites including the bone marrow, spleen, and thymus [45].

Hematopoietic stem and/or progenitor cell emergence has also been shown to occur within the vascular plexi within the extra-embryonic yolk sac [13, 46, 47], placenta [18], as well as the vitelline artery, umbilical arteries [21, 48, 49], endocardium [50], and head arteries [51]. Multiple real-time imaging studies demonstrating hematopoietic cell emergence from vascular endothelium have been performed in mice and zebrafish [52-54]. Single cell lineage tracing studies have demonstrated multipotent HSPC with cell surface markers CD31 (endothelial cell marker), CD41 (blood cell marker), c-Kit (stem cell growth factor receptor), and SCA-1 (stem cell antigen, also known as Ly6A) arising directly from the ventral wall of the murine dorsal aortae that can be traced to the fetal liver [53], and ultimately to the adult hematopoietic system in mice [45] and in zebrafish [52, 54].

Several studies have addressed the question of whether vascular-derived hematopoiesis truly originates from endothelial cells and is not mesenchymal in origin. In 2002, de Bruijn and colleagues demonstrated using a Ly6A(SCA1)-GFP transgenic mouse model that all hematopoietic stem cells within the developing aorta are Ly6A-GFP+ and that these cells localize to the endothelial layer of the dorsal aorta, but not to the underlying mesenchyme [55]. To further support the assertion that HSPC are generated from an endothelial intermediate and not the underlying mesenchyme, it has been demonstrated that key hematopoietic regulators such as the transcription factor RUNX1 are expressed at high levels by endothelial cells in hemogenic vascular sites in vertebrates [56]. North and colleagues further demonstrated that while RUNX1-expressing HSC are found in both endothelial and mesenchymal cell fractions in the mouse embryo, the presence of two functional Runxl alleles segregates HSC to the endothelial fraction only [57]. More recently, it has been shown that Runxl deletion in VE-cadherin expressing endothelial cells results in loss of intra-aortic hematopoietic cluster formation, again corroborating the link between cells of endothelial origin giving rise to hematopoietic clusters via the action of known hematopoietic mediators such as RUNX1 [58]. Additionally, murine AGM-associated hemogenic endothelial cells give rise to either hematopoietic or endothelial lineages but never both [59] and human pluripotent stem cell-derived arterial endothelial cells and hemogenic endothelial cells can be distinguished on the basis of CD184 and CD73 expression [60].

These studies collectively demonstrate, on a functional as well as morphological level, a strong body of evidence for the existence of hemogenic endothelial cells of exclusively vascular origin that give rise to multilineage HSPC during definitive hematopoiesis. However, much less is known about the mechanisms underlying hemogenic specification and their subsequent generation of HSPC.

\section{Characterization of hemogenic endothelium}

In order to characterize the molecular events underlying hemogenic endothelial cell specification and their subsequent generation of HSPC, it is necessary to delineate the phenotype of hemogenic vs. non-blood forming endothelium, so that they can be effectively isolated and studied. Isolation of these cells proves to be a difficult undertaking as hemogenic endothelium represents a small ( $\sim 1-3 \%$ of murine yolk sac and AGM endothelial cells) and transient population within hematopoietic tissues [13, 61].

To date, no definitive single marker to distinguish hemogenic from nonhemogenic endothelial cells has been identified. Building upon the body of evidence supporting the very existence of hemogenic endothelium, several groups have used flow cytometry techniques to elucidate the phenotypic identity of hemogenic endothelial cells within the yolk sac and AGM to aid in their isolation and further study. In 1997, Kabrun and colleagues described generation of HSPC from Flk1+ endothelium [62]. Shortly thereafter, Nishikawa and colleagues isolated VEcad+CD45-Ter119- cells from the yolk sac and caudal half of embryo proper of E9.5 mouse embryos and demonstrated that this cell fraction was capable of giving rise to lymphohematopoietic cells in culture. This study confirmed that the VE-cad+ cell fraction co-expressed vascular markers CD34, CD31, and Flk-1, confirming that the isolated cells were indeed endothelial in origin and confirming both the existence and functional capability of hemogenic endothelium to give rise to blood progenitors [63]. The need for VE-cadherin expression was further corroborated by a subsequent study by Fraser and colleagues that demonstrated long term lyphohematopoietic reconstitution potential of VE-cad+/CD45 - cells injected into irradiated neonatal mouse recipients [30]. Hemogenic endothelial cells can also be distinguished from nonhemogenic endothelial cells based on differential activity of a regulatory element of a KDR promoter enhancer such 
that only nonhemogenic endothelial cells activate the enhancer [64]. Other studies have since shown that cells co-expressing CD31, CD34, and Flk-1 from both murine and human yolk sac and AGM have demonstrated lymphoand lymphomyelopoietic potential under culture conditions $[1,63,65]$. In addition, cells co-expressing Flk-1 and VEcadherin exhibit enhanced colony forming ability when compared to Flk-1+VE-cad- cells [30]; however, VEcadherin expression was not found to be necessary for the blood-forming ability of yolk sac hemogenic endothelial cells in mice [13] or for transition of hemogenic endothelial cells to HSC in zebrafish and mice [66]. It has been shown as well that hemogenic endothelial cells may actually be divided into functionally distinct populations that either generate erythroid and myeloid progenitor cells or exclusively generate HSC [67].

Alpha4-integrin ( $\alpha 4$-integrin) has been identified as a marker that distinguishes hemogenic VE-cad+ cells from nonhemogenic VE-cad+ cells [68]. Live cell time-lapsed imaging of embryonic stem cell-derived Flk1+VE-cadmesodermal cells co-cultured with OP9 stromal cells demonstrated transformation of VE-cad+DI-acyl LDL+ cells with Claudin5 mediated-tight junctions into sheets of cells with endothelial morphology that gave rise to non-adherent, free-floating round CD45+CD41+ hematopoietic progenitor cells [69]. Loss of endothelial markers and acquisition of hematopoietic markers was shown to proceed in a patterned fashion in this model. More recently, a critical role for Stem cell leukemia (SCL) factor in maintenance of hemogenic competence and prevention of cardiomyocyte programming of primitive vascular endothelial cells has been identified [70]. In other recent studies, single hemogenic and non-hemogenic endothelial cells could be isolated from Runxl enhancer-reporter mice, which was beneficial for transcriptional profiling of these cell types [59, 69].

Further phenotypic characterization of hemogenic endothelial cells by our group has revealed that bloodforming activity of both yolk sac and AGM tissues is contained within the Hoechst dye effluxing, or "side population" (SP) fraction of cells $[13,61,71]$, which is not surprising given that the SP phenotype is also a characteristic of HSC within adult bone marrow [72]. SP cells within the yolk sac and AGM were further fractionated based on endothelial and hematopoietic cell surface markers, and the phenotype of hemogenic endothelium therein has been defined, on a clonal level, as Flk-1+c-Kit+CD45-SP cells $[13,61,71]$. In addition, the Flk-1+c-Kit+CD45- SP hemogenic endothelial cells were demonstrated to give rise to multilineage HSPC that are Flk1-c-Kit+CD45+ SP cells [13], that can be distinguished from mature blood cell types with a Flk1-CD31 \pm CD45+ non-SP phenotype.

\section{Specification of hemogenic endothelium}

Despite these knowledge gains about the characteristics of hemogenic endothelium over the last decade, little is known about the hierarchy of molecular events that govern their specification from non-blood forming endothelium, as well as the events that lead to their generation of HSPC. However, this body of knowledge is growing and recent advances in our understanding are discussed below (and are summarized in Fig. 1).

\section{Retinoic acid signaling}

Retinoic acid (RA) is known to regulate murine endothelial cell development and specification [73, 74]. Biologically active retinoic acid, known as all-trans retinoic acid (ATRA), is derived from retinol (Vitamin A) via oxidation by retinaldehyde dehydrogenases (RALDH1-3). ATRA is then released, taken up by target cells, and bound to members of the retinoic acid receptor (RAR) family $(\alpha, \beta$, or $\gamma$ ). Heterodimerization of RAR family members with rexinoid receptors (RXR) $\alpha, \beta$, and $\gamma$ form active transcription factor complexes that bind to retinoic acid response elements within target genes to initiate transcription (reviewed in Marcelo[1] and Chanda [75]).

During vasculogenesis in the murine yolk sac, active RA is generated by RALDH2 expressed in the visceral endoderm, which then signals within endothelial cells in the adjacent mesoderm that selectively express RAR $\alpha-1$ and $\alpha-2$ [73]. Raldh2-/- mutant embryos exhibit abnormal vascular development, due to hyperproliferative endothelial cells [74], as well as anemia, and die around E10.0 [76]. Other work has demonstrated that mice deficient for RA receptors have impaired fetal hepatic erythropoiesis [77] as well as impaired generation of marrow-derived HSC [78]. Because of its essential role in endothelial cell development, as well as embryonic and postnatal hematopoiesis, RA signaling is of great interest in the study of specification of endothelial cells to a hemogenic state.

Although Raldh1 and Raldh3 null embryos have not been shown to exhibit hematologic defects [79], embryos lacking Raldh2 were shown to exhibit defects in definitive, but not primitive hematopoiesis [13, 75]. In addition, we found that the underlying hematopoietic defect in Raldh2-/- mutants is lack of hemogenic endothelial cell development, which could be rescued via provision of bioactive RA to Raldh2-/- embryos in utero or in culture $[13,61]$. RA signaling is critical for the development of hemogenic endothelial cells within the yolk sac, as well as AGM. In both tissues, $\sim 90 \%$ of endothelial cells with active RA signaling exhibit a hemogenic phenotype; in addition, $\sim 90 \%$ of hemogenic endothelial cells are 
A

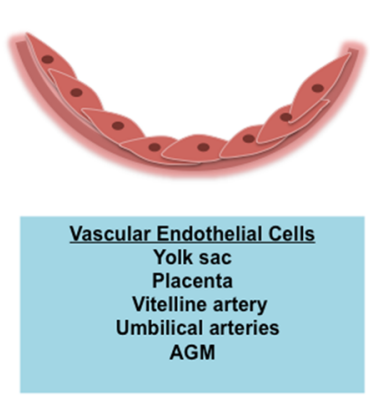

B

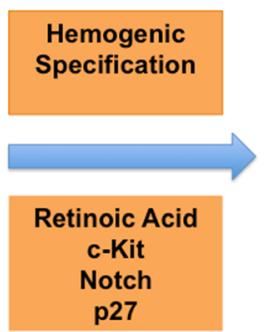

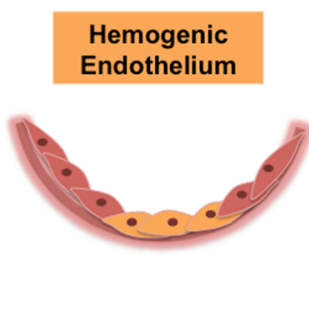

C

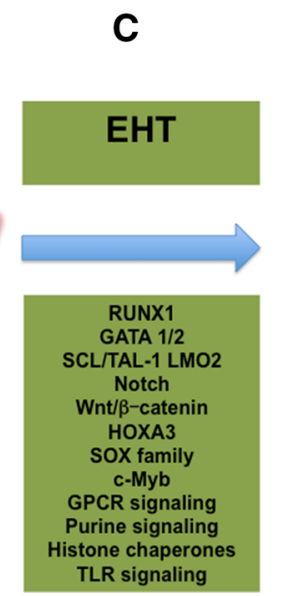

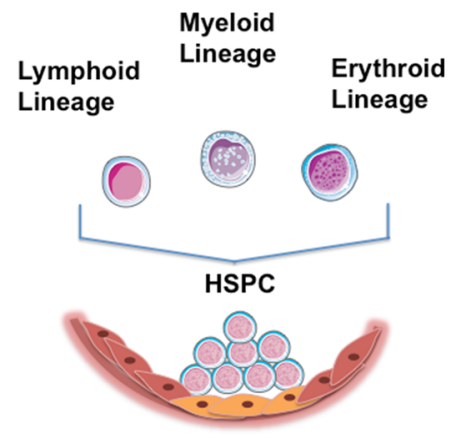

Fig. 1 Summary of regulation of primitive hematopoietic specification and generation of hematopoietic stem cells during embryonic development. a Schematic representation of endothelial layer of developing vascular wall (pink), listed are intra- and extraembryonic sources of vascular endothelial cells with hemogenic potential (blue

undergoing active RA signaling during definitive hematopoiesis in these tissues $[61,75]$. These findings place RA at or very near the top of the signaling hierarchy governing hemogenic endothelial cell specification and function during definitive hematopoiesis [13].

\section{Notch}

The Notch signaling pathway is evolutionarily conserved and involved in many aspects of embryonic development, with notable roles in vascular and cardiac development. Mammals express four members of the Notch family of receptors (Notch1-4) and five ligands: Delta-like 1, 3, 4 (DLL) and Jagged 1 and 2 (Jag). The interactions between the receptors and ligands allow signal transduction between neighboring cells via a multistep proteolytic cleavage of the Notch receptor and subsequent release of the Notch intracellular domain (NICD) (reviewed in High 2008 [80]). A $\gamma$-secretase complex powers the final step of release of NICD into the cytoplasm, wherein NICD can then enter the nucleus to form active transcriptional complexes with RBPJ, and co-activator Mastermind-like (MAML) [80]. The pathway itself appears straightforward, in theory, but is regulated by several positive and negative feedback loops whose actions are determined by both cellular context, developmental timing, and local environment [80].

Notch signaling is well known to be involved in cell fate decisions and cell differentiation, particularly in endothelial and blood cells, and a growing body of evidence also points toward its involvement in hemogenic specification. Embryos lacking Notch1 or Notch1 and Notch4 receptors, the only receptors expressed by endothelial cells [81, 82], exhibit abnormal vascular development similar to Raldh box). b Schematic representation of progression of events and molecular signals governing hemogenic specification (orange boxes) and $\mathbf{c}$ endothelial to hematopoietic transition (green boxes), ending with generation of intra-vascular hematopoietic clusters and multilineage hematopoietic stem and progenitor cells (HSPC)

2-/- mutants [74, 83, 84], and the expression of Notch1, and its downstream effectors HES1 and HEY1, which are known to regulate hematopoiesis [85] are upregulated in endothelial cells by RA [61]. In addition, chemical inhibition of Notch signaling in E8.0 wild-type mouse embryos via use of $\gamma$-secretase inhibitor DAPT suppresses yolk sac hemogenic endothelial cell specification [61]. Notch1, specifically, is expressed in the ventral wall of the dorsal aorta where hemogenic endothelium forms (reviewed in Jang 2015 [86]), and the AGM of Notch1-/- mutants exhibit decreased hematopoietic activity (reviewed in Zape 2011 [37, 87]). Conversely, Notch1 induction in murine embryonic stem cells leads to an expansion of VEcad+hemogenic endothelial cells with enhanced hematopoietic potential [86]. These data collectively suggest that Notch1 receptor signaling may regulate hemogenic endothelial cell specification and function, and also place Notch downstream of RA in the signaling hierarchy governing hemogenic specification.

\section{c-Kit}

c-Kit (CD117) is a growth factor receptor with tyrosine kinase activity known to bind stem cell factor (SCF), which leads to dimerization of receptors and subsequent activation or regulation of kinase activity that modulates intracellular signal transduction pathways involved in cellular proliferation, maintenance and migration [1]. Such pathways include Src kinase, PI3K, JAK-STAT, MAPK, and PLC $\gamma$, as well as regulatory PTPases, phosphatidylinositol phosphatases, and protein kinase C [88]. SCF is known to support multilineage hematopoietic development [88] and c-Kit mutations are associated with embryonic 
lethality at midgestation, anemia and disrupted HSC development $[88,89]$. As previously noted, the expression of c-Kit is a distinguishing feature of hemogenic endothelial cells, relative to non-blood forming endothelial cells. In addition, Notch1 expression in endothelial cells is upregulated downstream of c-Kit; thus, this pathway appears to play a critical, yet still undefined role, in the signaling hierarchy that governs hemogenic endothelial cell specification [61].

\section{Cell cycle control/p27}

Retinoic acid-deficient and Notch-inhibited embryos similarly exhibit endothelial cell hyper-proliferation, and impaired hemogenic endothelial cell development. We found that downregulation of cell cycle inhibitor p27, which induces $\mathrm{G} 1$ arrest [73, 74], to be the underlying defect in RA-deficient embryos. Furthermore, p27 is upregulated downstream of Notch and c-Kit, and lentivirus mediated re-expression of p27 in both RA- and Notchinhibited murine yolk sac endothelial cells rescues endothelial cell cycle control, hemogenic specification, and the generation of HSPC [61]. Given that cell cycle state and duration of G1 phase have been shown to be determinants of stem cell fate [90-92], it is possible that endothelial cells must be arrested in G1 phase in order to undergo hemogenic specification. In fact, several transcriptional regulators of definitive hematopoiesis are differentially expressed in G1 phase (reviewed extensively in [93]). It is also possible that p27 functions as a transcriptional regulator to directly alter endothelial cell phenotype, given that it can repress multipotency genes in stem cell populations [94]. Thus, the RA/c-Kit/Notch signaling axis which mediates p27 expression may regulate hemogenic specification in at least two ways: (1) via repression of genes that maintain a multipotent state in primordial endothelial cells or induction of hemogenic genes; and/or (2) elongation of G1 phase of cell cycle to enable expression and accumulation of transcriptional regulators that alter endothelial cell phenotype [61].

\section{Generation of hematopoietic stem/progenitor cells from hemogenic endothelium}

The process by which HSC are generated from hemogenic endothelium is referred to as the endothelial-to-hematopoietic transition (EHT; depicted in Fig. 1). In order to be able to derive HSC from pluripotent stem cells for clinical and research applications, an understanding of the events that lead to HSC formation from endothelial cells in vivo is required. The events leading to HSC generation from an endothelial intermediate at multiple anatomic sites, including the yolk sac, placenta, and AGM, involves an incompletely characterized complex interplay between microenvironment, developmental timing, and transcriptional regulation of fate.

\section{The AGM as a source of HSC}

Prior to the onset of circulation, it has been shown that lymphocyte and myeloid progenitors emerge as early as E7.5 within the para-aortic splanchnopleura (pSp) [6] and that explants of $\mathrm{pSp}$ demonstrate long-term hematopoietic reconstitution ability whereas yolk sac explants demonstrate only short term myeloid reconstitution ability [7]. Similar results were found in Xenopus studies that demonstrated HSC emergence from dorsal aortic tissue that derived from a blastomere independent of the yolk sac [95]. The implication of this is that long-term repopulating stem cells, or HSC, are intra-embryonic in origin. Work by several groups led to the discovery of intra-aortic hematopoietic clusters (IAHC) arising from the endothelial lining of ventral wall of the dorsal aorta prior to their release into circulation and eventual long-term colonization of fetal liver and marrow, thus corroborating the intraembryonic origin of HSC [43, 53, 55, 57, 96-101]. IAHC have been shown to appear around E9.5 in the AGM, and peak emergence of HSC from them occurs between E10.5 and E11.5 [21-23, 96].

The cellular composition and function of IAHC before and during HSC detection has been investigated, although to date a unified cell surface marker profile of HSC generated within the embryo has not been identified, presenting an important roadblock to furthering our understanding of EHT. IAHC at E10.0 were found to be phenotypically heterogeneous and contain very few progenitors (average of 22), but notably contain pre-HSC (average of 12) capable of long-term multilineage hematopoietic reconstitution post-transplantation [102]. A collection of hematopoietic, stem, and endothelial markers such as c-Kit, CD31, CD34, SCA-1, MAC1, VE-cadherin, Tie2, Flk-1 and CD45 have been shown to be expressed by HSC within the embryo, but these are also found on other cell types [47, 57, 99, 103-106]. Intra-aortic hematopoietic clusters have also been shown to be composed of pre-HSC that differentially express endothelial and hematopoietic surface markers including VE-cadherin, c-Kit, Ly6a, CD41 and CD45, suggesting that a post-hemogenic endothelial cell intermediate may exist along the transition from endothelial cell to HSPC within these intra-aortic clusters [53, 102, 106-108]. The remaining cell types within IAHC are yet to be identified, but are hypothesized to be comprised of these immature pre-HSC that will mature toward a HSC fate via EHT. Once the hematopoietic cluster phase of EHT is complete, data from chick studies show that the 
splanchnopleural endothelium in the aortic floor is replaced by somitic endothelial cells, in part offering an explanation for the very brief timeframe in which vascular hematopoiesis occurs during development [109], although this has not been shown in mouse models [110].

The dorsoventral polarity of IAHC emergence appears to be critical to governing their ultimate hematopoietic fate. This has been shown in the chick [111] and mouse [112] to be guided by local presence of mesenchymally derived prohematopoietic ventralizing (VEGF, bFGF, TGF- $\beta$, BMP4) or anti-hematopoietic dorsalizing factors (EGF and TGF$\alpha$ ), the downstream effects of each impact the expression of critical hematopoietic transcription factors that are involved in EHT [14, 111, 112]. Importantly, sub-aortic mesenchyme has not been shown to be a direct source of hematopoietic cells [45], thus corroborating the importance of these locally derived factors in driving hematopoietic specification of vascular endothelial cells. HSC have been found to have particular enrichment in the middle third of the E11.0 dorsal aorta, immediately adjacent to origin of the vitelline artery, suggesting that a disturbance in flow at the junction of these two vessels may interact with microenvironmental signals to drive HSC emergence [113]. The presence of hematopoietic mediators such as RUNX1 in the ventral aortic mesenchyme [56, 57], and upregulation of genes involved in cell death, adhesion, migration, as well as vascular development and hematopoiesis [113], coupled with restriction of definitive HSC localization to the ventral aorta [99] and evidence demonstrating that para/peri-aortic supporting cells also promote hematopoiesis [111,112,114-116], suggests that within the AGM there likely exists a specialized hematopoietic microenvironment or niche [117] powered by master transcriptional regulators, their downstream effectors, and extrinsic modifiers of these signaling cascades such as fluid shear stress $[118,119]$ that promote initial HSC development from hemogenic endotheliumthese are reviewed below.

\section{RUNX1}

RUNX1 (AML1) is a sequence-specific DNA binding protein that is part of a family of transcription factors called core binding factors (CBF), and an essential master regulator of EHT during aortic hematopoiesis [58, 120122]. Consistent with a role in EHT, RUNX1 deficiency in embryonic stem cells prevents the formation of blood cells from hemogenic endothelium [42]. It is expressed in all sites of definitive hematopoiesis in the embryo and precedes emergence of HSPC. Interestingly, this is conserved across all vertebrate species studied [123]. RUNX1 is expressed by mesenchymal cells in the dorsal aorta and AGM, placenta, and in hematopoietic cell clusters in ventral-dorsal aorta and vitelline and umbilical arteries [56, 57, 123], but its requirement, while critical for normal definitive hematopoietic development [124-126], as previously reviewed [14], is transient in embryonic development, and is not required during primitive hematopoiesis [42, 121] or after EHT [58]. RUNX1 expression has been shown to repress the endothelial program, while activating the hematopoietic program, as evidenced by sequential emergence of hematopoietic markers CD41 and later CD45 [42, 106, 108], at the time of transition from hemogenic endothelial cells to a hematopoietic cell fate [120, 123]. Deletion of Runxl does not prevent emergence of the CD41 marker on VE-cad+CD45-cells, but has been shown to prevent transition of these cells to CD41+CD45+ [127]. This patterned transition from endothelial cell phenotype to a hematopoietic phenotype is in part controlled by binding of multiprotein complexes containing GATA, Ets (PU.1) [128], and SCL family factors to Runxl enhancers known to be involved in HSC emergence $[14,129,130]$ and is also marked by loss of expression of genes associated with arterial identity, such as Soxl7 and Notchl [131], further supporting the idea of temporal transcriptional regulation governing cell fate as a central tenet of EHT.

Prospective isolation and transcriptional analysis of murine hemogenic endothelial cells using a transgenic Runxl enhancer-GFP reporter model has demonstrated that beginning at E9.5, hemogenic endothelial cells commit to hematopoietic lineage in an ordered fashion marked by an early gradual loss of endothelial potential and increase in hematopoietic potential. This occurs while the hemogenic endothelial cells still remain part of the endothelial wall [59]. The different stages of the transition from endothelial to hematopoietic cell have also been shown to be guided by the transcriptional activity of Runxl's two [132] promoter regions: the P1 (distal) and P2 (proximal) Runxl promoters control expression of Runxlc (distal) and Runxlb (proximal) isoforms [133, 134]. RUNX1b is expressed at low levels in hemogenic endothelium until E10.5 [135, 136], whereas RUNX1c expression is initiated within HSPC and loss of endothelial phenotype $[133,134,136]$. The P1 promoter element associated with RUNX1c expression is more complex than the $\mathrm{P} 2$ promoter and contains many binding sites for hematopoietic transcription factors [132]. RUNX1b transcriptome analysis reveals that it activates genes associated with cell adhesion, ECM remodeling, integrin signaling, and endothelial cell migration at the onset of transition from hemogenic endothelial cells to HSPC [133]. RUNX1 downstream targets such as GFI1/ GFI1B are also thought to promote down-regulation of endothelial proteins, thereby promoting a morphologic change from flattened endothelial cells to round cells [137]. Lack of GFI1B in embryos results in failure of release of 
hematopoietic cells from the extraembryonic yolk sac vasculature into circulation [137]. Generation of P1 and P2 RUNX1-EGFP zebrafish reporter lines demonstrated erythromyeloid progenitor emergence from the posterior blood island at $18 \mathrm{hpf}$ in the P1 line and definitive HSC emergence in the AGM region at $22 \mathrm{hpf}$ in the P2 line, further underlining the role of alternative Runxl promoter usage in cell fate determination via generation of spatially segregated yet temporally successive HSPC emergence [138]. Other work further demonstrated that the RUNX1c isoform was indeed only expressed at the time of emergence of definitive HSC (E10.5-11.5) in the mouse AGM and human (embryoid body day 12), but retroviral overexpression of both RUNX1 isoforms in mouse marrow and liver HSPC demonstrated no functional difference between either isoform in further generation of HSC, and induced quiescence in mouse HSC in vitro and in vivo. This suggests a developmentally important timeframe for the RUNX1c isoform in specification of HSPC from hemogenic endothelial cells at the time of EHT [139]. Other studies have identified a role for blood flow induced shear stress as a regulator of Runx 1 expression by the endothelium [118, 119].

Studies utilizing conditional deletion of Runxl, driven by Vavl promoter expression, a pan-hematopoietic gene, demonstrate that its hematopoietic requirement only extends through the transition from endothelium to HSPC [58]. Dependence on RUNX1 for generation of erythromyeloid progenitor cells begins at E7.5 [140] and ends around E10.5 [141]. Further study of requirement for RUNX1 in hematopoietic development utilized timed endothelial-specific deletion of RUNX1 activity showed that the transition to RUNX1 independent HSC formation occurs around E11.5 and does not require fetal liver colonization [141]. Tissue-specific restoration of RUNX1 function in murine Tie-2-expressing cells allowed for rescue of embryonic definitive HSC potential, allowing mutants to survive until birth without the previously described hemorrhagic phenotype observed in Runxl null embryos. These observations suggest that the primary embryonic lethal defect in Runxl mutants is indeed hematovascular in nature [142]. In adults, deletion of Runxl does not cause a reduction in HSPC numbers in the marrow; in fact, it causes an expansion of these cell types [123] and leads to hematologic abnormalities, such as increased myeloproliferation with neutrophilia, thrombocytopenia, and increased extramedullary hematopoiesis [143]. In the absence of RUNX1 during development, primitive erythropoiesis proceeds normally, hemogenic endothelium develops, but neither generation of myeloid and lymphoid progenitors, nor HSC generation occurs (reviewed in [14]), leading to an absence of IAHC and fetal liver HSC [54, 56, 57, 144], and ultimately death by E12.5
[144]. Interestingly, studies of hematopoietic tissues from Runxl haploinsufficient embryos yields variable degrees of HSC generation depending on the tissue type isolated, such that cultured mutant AGM explants yield fewer HSC than wild-type, and yolk sac and placental tissues yield increased numbers of HSC [145]. On the other hand, AGM-derived HSC from Runxl haploinsufficient mice that are directly transplanted into irradiated recipients without an intermediate culture step demonstrates increased generation of HSC [57]. Collectively, this body of evidence strongly supports a role for RUNX1 as a critical regulator of EHT, and that modification of its expression via interaction with associating proteins within specific tissue microenvironments and developmental time points, as well as under different physiologic conditions, impacts regulation of the hematopoietic transition [14, 124, 145].

\section{SCL/LMO/GATA}

The regulatory regions of hematopoietic genes are known to be bound by RUNX1, as discussed, as well as a transcription factor complex composed of stem cell leukemia protein (SCL)/T cell acute lymphocytic leukemia protein-1 (TAL-1), LIM domain only 2 (LMO2), GATA1, and GATA2 ([1, 140, 146-148], all of which have been implicated in EHT. LMO2 is thought to act as a bridge between SCL/TAL-1 and GATA-binding proteins in a transcriptional activating complex that drives vertebrate hematopoietic specification (reviewed in [1]).

Studies of Scl/Tal-1, Lmo2, and Gatal/2 mutant mouse embryos demonstrate that deletion of each gene results in midgestation lethality and impaired definitive hematopoiesis [149-152]. SCL is a helix-loop-helix transcription factor that functions upstream of RUNX1, and has been shown to be a critical regulator of hematopoiesis via generation of Tie-2hi c-Kit+CD41- hemogenic endothelium [42].

SCL loss-of-function studies show that hematopoiesis is impaired at both the level of stem cell formation and subsequent differentiation [153]. Interestingly, multiple isoforms of SCL [SCLA (full length) and SCLB (N-terminal truncated)] have been identified [153], and may play differential roles in definitive hematopoiesis. In vivo time lapse imaging studies demonstrated selective SCLB isoform expression in the dorsal aorta of hemogenic endothelium just prior to EHT, and this isoform may act upstream of RUNX1 to mediate EHT. SCLA, on the other hand, is expressed in HSC after the EHT process, and is critical for maintenance of these newly born cells within the AGM [153].

GATA2 is expressed by the para-aortic splanchnopleura and AGM regions of the mouse embryo [154]. It has been shown to have a role in production and expansion of HSC 
in the AGM during embryogenesis as well as normal expansion of the adult HSC pool within the bone marrow [155]. Gata2 deficient mice die at E10.5 due to defective primitive erythropoiesis and lack of HSPC generation [151]. Conditional deletion of a Gata 2 cis regulatory element in mouse AGM results in reduced expression of hematopoietic transcription factors SCL and RUNX1, and hemogenic endothelial cells of the mutants fail to generate HSPC, leading to embryonic lethality by E13-14 [156]. Additionally, VE-cadherin-driven deletion of Gata2 prevents generation of intra-aortic clusters in mouse dorsal aorta and results in a deficiency of long-term repopulating HSC [157]. Embryonic stem cells derived from adult chimeric mice deficient in $L M O 2$ also fail to contribute to the endothelium of large vessels [158, 159] and blood cell production [158, 159]. Morpholino knockdown of either Scl [147] or Lmo2 [160] in zebrafish results in similarly impaired expression of hematopoietic genes and loss of IAHC. Collectively, these findings implicate this group of transcription factors as having essential roles in EHT and definitive hematopoiesis.

\section{Notch}

In addition to the previously discussed role for Notch signaling in hemogenic specification, Notch has also been shown in a number of vertebrate studies to be essential for definitive HSC emergence in the embryo [87, 161, 162]. It is thought that Notch signaling mediates HSC development via EHT by interactions between emerging HSPC expressing Notch receptors and underlying endothelial cells and stroma expressing Notch ligands [163, 164]. Notch1 and Notch4 receptors are expressed specifically in the endothelial cell layer of the dorsal aorta, and Notch signaling pathway components such as DLL4, Jag1, Jag2, HES1, HRT1, HRT2, and GATA2 are expressed in both the endothelial cell layer of the dorsal aorta and its emerging hematopoietic clusters beginning between E9.5 and E10.5 [165-167]. Mouse and zebrafish embryos that lack Notch signaling components demonstrate defective or absent definitive intra-embryonic hematopoiesis and inability to establish permanent self-renewing HSC (reviewed in $[1,165])$. In-vitro blockage of Notch signaling using DAPT has been shown to prevent EHT of cultured murine E9.5 pSP/AGM cells [163]. Activation of Notch signaling in a modified culture system of E11.0 pSp/AGM hemogenic endothelial cells on immobilized chimeric human DLL1 results in emergence of multilineage hematopoietic progenitor formation with long-term engraftment capability [163], further supporting the critical role of Notch in driving early hematopoiesis.

HSC generation in the hematopoietic clusters of the murine AGM has been shown to mostly depend on Notch ligand Jag1 and its regulation of Gata2 expression [167]. The Gata2 promoter region contains two RBPJ binding sites involved in Notch-mediated activation [168] and not surprisingly, deletion of Notch transcriptional co-activator RBPJ leads to loss of HSPC, as well as loss of GATA2 expression, which is necessary for continued differentiation of hematopoietic cells [166, 169]. Notch-dependent GATA2b expression has been demonstrated to be required for RUNX1 expression within zebrafish dorsal aorta from a very early developmental stage, and its expression is limited to emerging HSC [170]. Embryos deficient for Notch1 downstream targets HES1 and HES5 have been shown to have intact arterial specification but have notable hematopoietic defects marked by abnormal proliferation of nonfunctional HSPC and increased expression of hematopoietic regulators including GATA2, RUNX1, and c-Myb [168]. Further interrogation of the Gata2 promoter region in this study revealed that in addition to containing RBPJ binding sites essential for initiation of hematopoiesis, it also contained HES binding sites necessary for Gata2 downregulation involved in driving functional hematopoiesis [168]. This highlights the complexity of Notch signaling in this context, as both driving expression of and concomitantly negatively regulating a key hematopoietic mediator.

Previous work showing that different Notch ligands confer different signal strengths $[171,172]$ has formed the basis for recent work suggesting that determination of endothelial versus hematopoietic fate in the developing AGM is mediated by ligand-specific differences in Notch1 signal strength. Use of high and low sensitivity Notch1 activation trap mouse models demonstrated that hematopoietic specification and repression of the endothelial program is driven by low levels of Jag1 mediated Notch signaling. In the absence of Jag1, DLL4 mediated high levels of Notch activity instead drives the endothelial/arterial program [173]. The authors of this study propose a model wherein Jag1 antagonizes DLL4-mediated high Notch signaling in a subset of endothelial cells to drive them toward a hematopoietic fate rather than an endothelial fate [173]. This further highlights the critical role of Jag1, as previously discussed, in driving EHT and importantly also adds to the body of evidence that endothelial and hematopoietic cells represent distinct lineages.

In human embryonic stem cells, Notch activation has also been demonstrated to be necessary for generation of CD45 + cells, and Notch signaling via HES1 is necessary for their hematopoietic differentiation [174]. Other studies in human embryonic stem cells showed that ligand DLL4 is induced via Notch signaling in a small subset of endothelial progenitors during hematopoietic differentiation, and the level of DLL4 expression appears to correlate with hematopoietic versus endothelial fate. That is, DLL4-high 
progenitors are enriched for endothelial potential, whereas DLL4low/- coincides with acquisition of hematopoietic potential [174]. Thus, a model has been proposed, wherein hemogenic endothelial cells are DLL4low/- and are Notch activated via neighboring DLL-high cells to promote transition from an endothelial state to CD45+ hematopoietic cells that cluster in a fashion similar to intra-aortic hematopoietic clusters in the AGM [174]. Related studies also demonstrated a functional role for DLL4 in promoting specification of hematopoietic cells from hematoendothelial progenitors, wherein expression of DLL4 increased numbers of clonogenic hematopoietic progenitors, and interestingly skewed their fate toward an erythroid lineage [174]. No correlation between levels of Jag1 or Jag2 expression was noted with respect to generation of hematoendothelial progenitors or hematopoietic precursors there from, as has been noted in other vertebrate studies, suggesting that human HSC differentiation may be affected by other Notch ligands [174].

A recent study investigated Notch-regulated elements involved in control of HSC generation in zebrafish, mouse, and human embryonic tissues. ChIP on ChIP analysis against Notch co-activator RBPJ was performed and identified candidate promoter regions of genes regulated by Notch in hemaotpoietic tissues. The most significant result was enrichment of $\mathrm{Cdca}$, which is shown to recruit RBPJ, as well as Notch1 ICD. CDCA7 expression was shown to be upregulated in the hemogenic population derived from human embryonic stem cells in a Notch-dependent manner. Down-regulation of $\mathrm{Cdca} 7 \mathrm{mRNA}$ was shown to induce hematopoietic differentiation and concomitantly decrease HSPC numbers, suggesting that it is a Notch-mediated target involved in emergence of HSPC, but not differentiation of these cells [175].

\section{Wnt/ $\beta$-catenin}

There is evidence that Notch, Wnt, and BMP pathways interact to generate HSC in the zebrafish embryo and also are involved in driving hematopoietic development from embryonic stem cells $[176,177]$. Wnt is a well-described evolutionarily conserved signaling pathway known to modulate many areas of embryonic development. The Wnt ligands are a family of 19 glycosylated proteins that bind Frizzled receptors and LDL receptor protein co-receptors to trigger a variety of downstream responses including activation of $\beta$-catenin (canonical pathway) and/or JNK and PKC (noncanonical pathway) that modulate gene expression programs critical for normal embryonic development (reviewed in [176]). Early evidence that $\mathrm{Wnt} / \beta$ catenin has a role in embryonic hematopoiesis came from zebrafish studies showing Prostaglandin E2 mediates HSC formation in the AGM via $\beta$-catenin [177]. Recently, it has been shown that EMP cells emerging from vascular endothelium in the yolk sac do so independent of vascular identity or the influence of circulation, but their emergence requires intact Wnt signaling [12]. It has been shown that $\mathrm{Wnt} / \beta$-catenin activity is transiently required in the AGM of mouse embryos for emergence and generation of longterm HSC, as well as production of hematopoietic cells in vitro from AGM endothelial precursors [176]. Hemogenic endothelial cells from AGM at E11.5 have also been shown to have a high degree of active Wnt signaling, as evidenced by the presence of high levels of $\beta$-catenin in cells lining the dorsal aorta, close to emerging hematopoietic clusters, but not in cells budding off of endothelium or within circulating plasma [75]. In human pluripotent stem cell models of EHT, hemogenic endothelium undergoes EHT toward either a primitive or definitive hematopoietic fate depending on presence of either inactive (primitive) or active (definitive) Wnt signaling [178]. This body of evidence suggests a contextspecific role for Wnt such that it is required for the generation of hemogenic endothelium and likely initiation of EHT but gradually becomes downregulated as HSPC are generated [75].

\section{HOX/SOX}

Homeobox genes, such as Hox and Sox genes, play a key role in determining cell identity during embryonic development [179-182]. Hox paralogue group 3 (HOXA3), specifically, has an important role in endothelial and cardiovascular development (reviewed in [183]). Its expression was found to be high in embryonic mesenchymal tissue, intermediate in the dorsal aorta and absent from the yolk sac at E8.25 and E8.5 when definitive hematopoiesis is occurring in that tissue. This is consistent with the idea that it prevents hematopoietic differentiation of endothelial progenitors via down-regulation of RUNX1, GATA1, GFI1b, Ikaros and PU.1. Conversely, downregulation of HOXA3 is concomitant with increased RUNX1 expression within the aortic endothelium, and its re-expression in embryonic stem cells, as well as cultured mouse embryonic tissues, causes retention of an endothelial phenotype. These data suggest an important role for HOXA3 in maintenance of an endothelial state prior to hematopoietic transition [183]. Ectopic expression of another Hox paralogue, HOXB4, in yolk sac derived hematopoietic progenitor cells has been shown to drive conversion to a definitive HSC phenotype with long-term engraftment potential [184]. Additionally, several transcriptional regulators of the definitive hematopoietic program such as RUNX1, SCL/TAL1, GATA2, and GFI1 have been shown to be direct targets of HOXB4 in embryonic stem cell-derived hematopoietic progenitors [185]. 
SOX17 is a transcription factor expressed in AGM hemogenic endothelium downstream of HOXA3 [183] at E8.5-8.75, and in addition to its role as a critical factor governing arterial identity [186], it has been shown to be required for generation of fetal and neonatal HSC [187]. Although SOX17 is not required for the generation of adult HSC [120], its overexpression in adult hematopoietic progenitors has been shown to confer fetal HSC characteristics [188]. Additionally, SOX17 can drive expansion of cells that exhibit downregulation of endothelial markers and also possess an ability to generate hematopoietic cells [120, 187, 189]. Loss of Sox 17 decreases expression of Notch1 in the murine AGM, suggesting that SOX17 mediates generation of hemogenic endothelium via Notch signaling during definitive hematopoiesis [187]. Conditional loss of SOX17 mediated repression of Runxl and Gata2 recently has been shown to result in increased production of hematopoietic cells from murine AGM endothelial cells that can be dampened by an increase in Notch signaling [131], suggesting that following hemogenic specification, SOX17 modulates hemogenic endothelium by active repression of the hematopoietic program by the SOX17/ Notch axis until initiation of EHT. This has been complemented by studies of murine AGM hemogenic endothelial cells undergoing EHT using combined correlative scanning electron microscopy and immunofluorescence demonstrating an increase in RUNX1 levels concomitant with decrease in nuclear SOX17, rounding of previously flattened AGM endothelial cells, and the onset of co-expression of CD41 and c-Kit on these newly rounded cells [190]. SOX17 has also recently been shown to be necessary for commitment to the definitive erythroid lineage [191]. Other closely related SOX family members, SOX7 and SOX18, have a role in primitive hematopoiesis. SOX7 and SOX18 have transient expression in hematopoietic precursors at the onset of blood specification and expression of these in early hematopoietic precursors from mouse embryonic stem cells and embryos enhances their proliferation while blocking their maturation [189, 192, 193].

\section{cMyb}

The transcription factor $\mathrm{cMyb}$ was originally identified as a nuclear protooncogene involved in certain avian cancers but is also expressed in HSPC prior to their differentiation. Multiple mouse studies utilizing $c M y b$ mutants demonstrate the key role played by cMyb within a variety of hematopoietic pathways such as lymphoid development, HSPC maintenance, and HSPC differentiation [194]. Deletion of $c M y b$ results in murine embryonic lethality at E15.5 due to lack of fetal liver hematopoiesis, specifically impaired erythroid and myeloid development [195]. AGM explants from $c M y b-/-$ mutant mice also yield 100-fold fewer HSPC [196]. Loss of function studies in zebrafish have shown similarly impaired definitive hematopoiesis, even in the setting of otherwise normal primitive hematopoiesis [197, 198]. Zebrafish studies have also demonstrated accumulation of HSPC within the ventral wall of the dorsal aorta, their site of origination, and that this failure of migration to a hematopoietic niche such as the zebrafish caudal hematopoietic tissue and kidney may in part underlie the previously demonstrated failure of definitive hematopoiesis in $c M y b$ mutants [194].

\section{Other mediators of HSPC generation from hemogenic endothelium}

\section{G-protein coupled receptors}

To identify candidate regulators of EHT on a global level, whole genome transcriptome analysis of murine aortic endothelial cells, hemogenic endothelial cells and HSPC populations has identified 530 differentially expressed genes during EHT with particular upregulation of the gene encoding $\mathrm{G}$ protein coupled receptor 56 (Gpr56) and heptad transcription factors SCL, LYL1, LMO2, GATA2, RUNX1, ERG, and FLI-1) [199, 200]. The heptad factors were been shown to bind to Gpr56 enhancer regions and regulate its expression, and knockdown of Gpr56 in zebrafish resulted in hematopoietic defects that could be rescued with either mouse or zebrafish Gpr56 RNA, thus establishing GPR56 as a novel regulator of EHT via a yet to be elucidated mechanism [199]. Another G protein coupled receptor, GPR183, has also recently been shown to dampen Notch signaling in zebrafish models via its recruitment of $\beta$-Arrestin- 1 and E3 ligase NEDD4, both of which degrade Notch1 in hemogenic endothelial cells to promote EHT [201].

\section{Purine signaling}

Purines (such as adenosine, ADP, and ATP) exhibit extracellular signaling activity that regulates diverse physiologic and developmental cellular functions including autoregulation of blood flow, cell proliferation and differentiation, and stem cell regeneration, all via cell surface receptors [202]. Adenosine signaling at the level of the vascular endothelium has recently been demonstrated to play a role in regulation of HSPC development in both zebrafish and mice. In a recent study, elevated adenosine levels in zebrafish embryos were shown increase numbers of RUNX1+/cMyb+ HSPC in the dorsal aorta via increased expression of CXCL8 (IL-8), which has been shown to trigger proliferation of hematopoietic progenitor 
cells [203]. Furthermore, in the same study, alteration of adenosine signaling via knockdown of the $A_{2 b}$ adenosine receptor resulted in disruption of both the generation of SCL+ hemogenic vascular endothelium and the endothelial to hematopoietic transition. These results were mirrored in mouse embryonic stem cell colony forming assays, as well as E10.5 AGM explants, that demonstrated an increase in production of multipotent progenitor colonies in the setting of increased adenosine signaling [202].

\section{Chromatin remodeling}

The role of reprogramming of transcriptional states in promoting lineage commitment in HSC continues to be of great interest in the field. The role of chromatin modification as an important mediator of transcriptional regulation of EHT has been investigated. Majumder and coworkers demonstrated that the histone chaperone HIRA (histone cell cycle regulation-defective homolog A) regulates RUNX1 activity during EHT. They showed that HIRA mediated histone acetylation of Runxl activates the downstream hematopoietic targets of RUNX1 and that in HIRA deficient mutants, there was not only reduced expression of Runxl, but also lack of chromatin reorganization necessary for appropriate RUNX1 binding and transcriptional activity to drive hematopoiesis [204]. Chromodomain helicase DNA-binding protein 1 (CHD1), an ATP-dependent chromatin-remodeling enzyme whose activation is associated with an increased level of total active transcription in mouse embryonic stem cells [205, 206] has also recently been shown to be essential for successful EHT. Endothelial-specific Chdl mutants, while able to produce intact E10.5 IAHC, that show intermediate markers of differentiation such as RUNX1 and c-Kit, do not successfully initiate definitive hematopoiesis and die by E15.5 due to severe anemia and absolute failure of erythropoiesis [207]. Analysis of cells from the mutant IAHC demonstrated that the cells in the clusters underwent apoptosis rather than hematopoietic specification, as evidenced by failure of expression of markers of hematopoietic lineage such as CD45, and a fivefold reduction in myeloid colony forming potential. Global gene expression analysis of Chdl mutant endothelium at E10.5 in this study was generally found to be unchanged when compared to wild-type endothelial controls, but notably lacked activation of a set of 156 genes implicated in hematopoiesis and growth. Furthermore, hematopoietic progenitors underwent a CHD-1 dependent elevation in global transcriptional at the time of EHT that was necessary for initial expansion and survival of HSPC but not for differentiation and maintenance of the differentiated HSC pool [207]. Committed hematopoietic progenitors with a Vav-Cre Chd-1 mutation demonstrated peripheral blood composition comparable to wild type mice at one year of age. Taken together, these results suggest a pointed critical role for CHD-1 mediated increased transcriptional output in order to successfully complete EHT and establish functional hematopoiesis, but that it is not required beyond the point of hematopoietic specification [207].

\section{Hypoxia and inflammation}

The intrauterine environment is notably hypoxic and via the action of hypoxia inducible factor transcription factors (HIF), transcription of genes necessary for promoting normal development in this environment is activated (reviewed in [208]). The midgestation AGM and placenta have been shown to exhibit localized areas of hypoxia including hematopoietic clusters and some underlying endothelial cells. The role of HIF1 $\alpha$ in regulation of embryonic hematopoiesis was recently shown to be necessary for generation of HSPC from the AGM from E9.0 to E11 [208].

Recently, an interesting link between Toll-like receptor 4 (TLR4) inflammatory signaling, a cascade previously associated with stress-induced hematopoiesis in adult marrow, and embryonic hematopoiesis has also been established. TLR4-NF- $\kappa B$ signaling was found to regulate hemogenic endothelium-derived HSPC development in both mice and zebrafish embryos via activation of Notch signaling [209]. This complements other recent studies investigating the role of non-infectious/sterile pro-inflammatory signaling via TNFa or interferon in HSPC development in zebrafish and mice [210-212], suggesting that a low-grade pro-inflammatory state is necessary for normal HSPC emergence even under low-stress conditions and may in fact prime the hematopoietic system for reactive hematopoiesis in the setting of exogenous stressors such as infection [209].

\section{Summary and conclusions}

In summary, the developmental hierarchy governing hematovascular development is complex and multifactorial and our understanding of it is still in its infancy. Over time the study of hematologic development has founded many concepts central to the field of stem cell research as a whole [213]. Hematopoietic development begins early in the mammalian embryo in the extra-embryonic yolk sac and placenta and peaks in the AGM region by E10.5. It is characterized by overlapping waves of generation of primitive blood cells, multilineage hematopoietic progenitor cells, and finally definitive long-term repopulating HSC via a hemogenic endothelial cell intermediate. Emergence of blood cells from hemogenic endothelium is known as 
the endothelial to hematopoietic transition, which is driven by an incredibly complex and yet to be fully elucidated interplay between developmental timing and tissue microenvironmental factors. This interplay is thought to govern a timed gradual loss of endothelial characteristics [105], accompanied by changes in level and type of expression of hematopoietic regulators such as RUNX1 $[56,99,142]$ beginning in the extraembryonic yolk sac, placenta and umbilical vessels, as well as the midgestation aorta, and possibly being completed in hematopoietic niches such as the fetal liver, and bone marrow [18, 19, 99, 102, 105, 106].

Still, there remain a number of unanswered questions surrounding the progression from embryonic mesoderm to endothelium to HSPC and adult HSC. Of particular interest, as already mentioned, is study of the tissue specific microenvironments in which these progenitor cells are generated and mature during development, and the role that microenvironment plays in driving the formation of multilineage HSPC [29]. To date, there is little evidence to support the existence of hemogenic endothelium in later stages of embryonic development or postnatally, but human cord blood hematopoietic progenitors have been shown to differentiate into endothelial precursors capable of generating functional vasculature in vivo and if further instructed by hematopoietic growth factors, first switch to transitional CD144+CD45+ cells and then to hematopoietic cells perhaps due to the influence of their tissue microenvironment [214]. This finding is of great interest, as it suggests that hemogenic endothelium is not as transient in nature as previously thought and may exist beyond the embryonic period as an untapped reservoir of hematopoietic potential for therapeutic applications [214]. Efficient generation and differentiation of hematopoietic cells in vitro to date has been fraught with technical difficulty and this difficulty is almost certainly exacerbated by a need for a more complete understanding of in vivo endothelial and hematopoietic development (reviewed in [215]).

Further study of these processes, from specification of hemogenic endothelium to generation of HSPC via EHT, and establishment of functional definitive hematopoiesis both in the prenatal and postnatal period, will further our understanding of developmental hematopoiesis, as well as adult hematopoiesis in both health and disease. It will also highlight the cellular and molecular underpinnings of the evolution of a population of stem and progenitor cells that hold great promise for use in clinical therapies for hematologic, oncologic, vascular, and immune-mediated pathologies.

Open Access This article is distributed under the terms of the Creative Commons Attribution 4.0 International License (http:// creativecommons.org/licenses/by/4.0/), which permits unrestricted use, distribution, and reproduction in any medium, provided you give appropriate credit to the original author(s) and the source, provide a link to the Creative Commons license, and indicate if changes were made.

\section{References}

1. Marcelo KL, Goldie LC, Hirschi KK (2013) Regulation of endothelial cell differentiation and specification. Circ Res 112(9):1272-1287. doi:10.1161/circresaha.113.300506

2. Lawson KA, Meneses JJ, Pedersen RA (1991) Clonal analysis of epiblast fate during germ layer formation in the mouse embryo. Development (Cambridge, England) 113(3):891-911

3. Palis J, Robertson S, Kennedy M, Wall C, Keller G (1999) Development of erythroid and myeloid progenitors in the yolk sac and embryo proper of the mouse. Development (Cambridge, England) 126(22):5073-5084

4. Corbel C, Salaun J, Belo-Diabangouaya P, Dieterlen-Lievre F (2007) Hematopoietic potential of the pre-fusion allantois. Dev Biol 301(2):478-488. doi:10.1016/j.ydbio.2006.08.069

5. Zeigler BM, Sugiyama D, Chen M, Guo Y, Downs KM, Speck NA (2006) The allantois and chorion, when isolated before circulation or chorio-allantoic fusion, have hematopoietic potential. Development (Cambridge, England) 133(21):4183-4192. doi:10. 1242/dev.02596

6. Cumano A, Dieterlen-Lievre F, Godin I (1996) Lymphoid potential, probed before circulation in mouse, is restricted to caudal intraembryonic splanchnopleura. Cell 86(6):907-916

7. Cumano A, Ferraz JC, Klaine M, Di Santo JP, Godin I (2001) Intraembryonic, but not yolk sac hematopoietic precursors, isolated before circulation, provide long-term multilineage reconstitution. Immunity 15(3):477-485

8. Haar JL, Ackerman GA (1971) A phase and electron microscopic study of vasculogenesis and erythropoiesis in the yolk sac of the mouse. Anat Rec 170(2):199-223. doi:10.1002/ar.1091700206

9. Lucitti JL, Jones EA, Huang C, Chen J, Fraser SE, Dickinson ME (2007) Vascular remodeling of the mouse yolk sac requires hemodynamic force. Development (Cambridge, England) 134(18):3317-3326. doi:10.1242/dev.02883

10. Gomez Perdiguero E, Klapproth K, Schulz C, Busch K, Azzoni E, Crozet L, Garner H, Trouillet C, de Bruijn MF, Geissmann F, Rodewald HR (2015) Tissue-resident macrophages originate from yolk-sac-derived erythro-myeloid progenitors. Nature 518(7540):547-551. doi:10.1038/nature13989

11. Hoeffel G, Chen J, Lavin Y, Low D, Almeida FF, See P, Beaudin AE, Lum J, Low I, Forsberg EC, Poidinger M, Zolezzi F, Larbi A, Ng LG, Chan JK, Greter M, Becher B, Samokhvalov IM, Merad M, Ginhoux F (2015) C-Myb(+) erythro-myeloid progenitor-derived fetal monocytes give rise to adult tissueresident macrophages. Immunity 42(4):665-678. doi:10.1016/j. immuni.2015.03.011

12. Frame JM, Fegan KH, Conway SJ, McGrath KE, Palis J (2015) Definitive hematopoiesis in the yolk sac emerges from wntresponsive hemogenic endothelium independently of circulation and arterial identity. Stem cells (Dayton, Ohio). doi:10.1002/ stem. 2213

13. Goldie LC, Lucitti JL, Dickinson ME, Hirschi KK (2008) Cell signaling directing the formation and function of hemogenic endothelium during murine embryogenesis. Blood 112(8): 3194-3204. doi:10.1182/blood-2008-02-139055

14. Dzierzak E, Speck NA (2008) Of lineage and legacy: the development of mammalian hematopoietic stem cells. Nat Immunol 9(2):129-136 
15. Adamo L, Garcia-Cardena G (2012) The vascular origin of hematopoietic cells. Dev Biol 362(1):1-10. doi:10.1016/j.ydbio. 2011.09.008

16. Kaimakis P, Crisan M, Dzierzak E (2013) The biochemistry of hematopoietic stem cell development. Biochim Biophys Acta 1830 2:2395-2403. doi:10.1016/j.bbagen.2012.10.004

17. Alvarez-Silva M, Belo-Diabangouaya P, Salaun J, DieterlenLievre F (2003) Mouse placenta is a major hematopoietic organ. Development (Cambridge, England) 130(22):5437-5444. doi:10.1242/dev.00755

18. Gekas C, Dieterlen-Lievre F, Orkin SH, Mikkola HK (2005) The placenta is a niche for hematopoietic stem cells. Dev Cell 8(3):365-375. doi:10.1016/j.devcel.2004.12.016

19. Ottersbach K, Dzierzak E (2005) The murine placenta contains hematopoietic stem cells within the vascular labyrinth region. Dev Cell 8(3):377-387. doi:10.1016/j.devcel.2005.02.001

20. Rhodes KE, Gekas C, Wang Y, Lux CT, Francis CS, Chan DN, Conway S, Orkin SH, Yoder MC, Mikkola HK (2008) The emergence of hematopoietic stem cells is initiated in the placental vasculature in the absence of circulation. Cell Stem Cell 2(3):252-263. doi:10.1016/j.stem.2008.01.001

21. de Bruijn MF, Speck NA, Peeters MC, Dzierzak E (2000) Definitive hematopoietic stem cells first develop within the major arterial regions of the mouse embryo. EMBO $\mathrm{J}$ 19(11):2465-2474. doi:10.1093/emboj/19.11.2465

22. Muller AM, Medvinsky A, Strouboulis J, Grosveld F, Dzierzak E (1994) Development of hematopoietic stem cell activity in the mouse embryo. Immunity 1(4):291-301

23. Medvinsky A, Dzierzak E (1996) Definitive hematopoiesis is autonomously initiated by the AGM region. Cell 86(6):897-906

24. Medvinsky AL, Samoylina NL, Muller AM, Dzierzak EA (1993) An early pre-liver intraembryonic source of CFU-S in the developing mouse. Nature 364(6432):64-67. doi:10.1038/ $364064 \mathrm{a} 0$

25. Morrison SJ, Hemmati HD, Wandycz AM, Weissman IL (1995) The purification and characterization of fetal liver hematopoietic stem cells. Proc Natl Acad Sci USA 92(22):10302-10306

26. Kumaravelu P, Hook L, Morrison AM, Ure J, Zhao S, Zuyev S, Ansell J, Medvinsky A (2002) Quantitative developmental anatomy of definitive haematopoietic stem cells/long-term repopulating units (HSC/RUs): role of the aorta-gonad-mesonephros (AGM) region and the yolk sac in colonisation of the mouse embryonic liver. Development (Cambridge, England) 129(21):4891-4899

27. Coşkun S, Chao H, Vasavada H, Heydari K, Gonzales N, Zhou X, de Crombrugghe B, Hirschi KK (2014) Development of the fetal bone marrow niche and regulation of HSC quiescence and homing ability by emerging osteolineage cells. Cell reports 9(2):581-590. doi:10.1016/j.celrep.2014.09.013

28. Takeuchi M, Sekiguchi T, Hara T, Kinoshita T, Miyajima A (2002) Cultivation of aorta-gonad-mesonephros-derived hematopoietic stem cells in the fetal liver microenvironment amplifies long-term repopulating activity and enhances engraftment to the bone marrow. Blood 99(4):1190-1196

29. Hirschi KK (2012) Hemogenic endothelium during development and beyond. Blood 119(21):4823-4827. doi:10.1182/blood2011-12-353466

30. Fraser ST, Ogawa M, Yu RT, Nishikawa S, Yoder MC, Nishikawa S (2002) Definitive hematopoietic commitment within the embryonic vascular endothelial-cadherin $(+)$ population. Exp Hematol 30(9):1070-1078

31. Sabin FR (2002) Preliminary note on the differentiation of angioblasts and the method by which they produce blood-vessels, blood-plasma and red blood-cells as seen in the living chick. 1917. J Hematother Stem Cell Res 11(1):5-7. doi:10. 1089/152581602753448496
32. Murray PDF (1932) The Development in vitro of the Blood of the Early Chick Embryo, vol 111. vol 773. doi:10.1098/rspb. 1932.0070

33. Dieterlen-Lievre F (1975) On the origin of haemopoietic stem cells in the avian embryo: an experimental approach. J Embryol Exp Morphol 33(3):607-619

34. Godin IE, Garcia-Porrero JA, Coutinho A, Dieterlen-Lievre F, Marcos MA (1993) Para-aortic splanchnopleura from early mouse embryos contains $\mathrm{B} 1 \mathrm{a}$ cell progenitors. Nature 364(6432):67-70. doi:10.1038/364067a0

35. Garcia-Porrero JA, Godin IE, Dieterlen-Lievre F (1995) Potential intraembryonic hemogenic sites at pre-liver stages in the mouse. Anat Embryol 192(5):425-435

36. Shalaby F, Ho J, Stanford WL, Fischer KD, Schuh AC, Schwartz L, Bernstein A, Rossant J (1997) A requirement for Flk1 in primitive and definitive hematopoiesis and vasculogenesis. Cell 89(6):981-990

37. Zape JP, Zovein AC (2011) Hemogenic endothelium: origins, regulation, and implications for vascular biology. Semin Cell Dev Biol 22(9):1036-1047. doi:10.1016/j.semcdb.2011.10.003

38. Motoike T, Markham DW, Rossant J, Sato TN (2003) Evidence for novel fate of Flk1+ progenitor: contribution to muscle lineage. Genesis (New York, NY: 2000) 35(3):153-159. doi:10. 1002 /gene. 10175

39. Huber TL, Kouskoff V, Fehling HJ, Palis J, Keller G (2004) Haemangioblast commitment is initiated in the primitive streak of the mouse embryo. Nature 432(7017):625-630. doi:10.1038/ nature 03122

40. Padron-Barthe L, Temino S, Villa del Campo C, Carramolino L, Isern J, Torres M (2014) Clonal analysis identifies hemogenic endothelium as the source of the blood-endothelial common lineage in the mouse embryo. Blood 124(16):2523-2532. doi:10. 1182/blood-2013-12-545939

41. Kinder SJ, Tsang TE, Quinlan GA, Hadjantonakis AK, Nagy A, Tam PP (1999) The orderly allocation of mesodermal cells to the extraembryonic structures and the anteroposterior axis during gastrulation of the mouse embryo. Development (Cambridge, England) 126(21):4691-4701

42. Lancrin C, Sroczynska P, Stephenson C, Allen T, Kouskoff V, Lacaud G (2009) The haemangioblast generates haematopoietic cells through a haemogenic endothelium stage. Nature 457(7231):892-895. doi:10.1038/nature07679

43. Jaffredo T, Gautier R, Eichmann A, Dieterlen-Lievre F (1998) Intraaortic hemopoietic cells are derived from endothelial cells during ontogeny. Development (Cambridge, England) 125(22): $4575-4583$

44. Sugiyama D, Ogawa M, Hirose I, Jaffredo T, Arai K, Tsuji K (2003) Erythropoiesis from acetyl LDL incorporating endothelial cells at the preliver stage. Blood 101(12):4733-4738. doi:10. 1182/blood-2002-09-2799

45. Zovein AC, Hofmann JJ, Lynch M, French WJ, Turlo KA, Yang Y, Becker MS, Zanetta L, Dejana E, Gasson JC, Tallquist MD, Iruela-Arispe ML (2008) Fate tracing reveals the endothelial origin of hematopoietic stem cells. Cell Stem Cell 3(6):625-636. doi:10.1016/j.stem.2008.09.018

46. Samokhvalov IM, Samokhvalova NI, Nishikawa S (2007) Cell tracing shows the contribution of the yolk sac to adult haematopoiesis. Nature 446(7139):1056-1061. doi:10.1038/nature05725

47. Yoder MC, Hiatt K, Dutt P, Mukherjee P, Bodine DM, Orlic D (1997) Characterization of definitive lymphohematopoietic stem cells in the day 9 murine yolk sac. Immunity 7(3):335-344

48. Zovein AC, Turlo KA, Ponec RM, Lynch MR, Chen KC, Hofmann JJ, Cox TC, Gasson JC, Iruela-Arispe ML (2010) Vascular remodeling of the vitelline artery initiates extravascular emergence of hematopoietic clusters. Blood 116(18): 3435-3444. doi:10.1182/blood-2010-04-279497 
49. Gordon-Keylock S, Sobiesiak M, Rybtsov S, Moore K, Medvinsky A (2013) Mouse extraembryonic arterial vessels harbor precursors capable of maturing into definitive HSCs. Blood 122(14):2338-2345. doi:10.1182/blood-2012-12-470971

50. Nakano H, Liu X, Arshi A, Nakashima Y, van Handel B, Sasidharan R, Harmon AW, Shin JH, Schwartz RJ, Conway SJ, Harvey RP, Pashmforoush M, Mikkola HK, Nakano A (2013) Haemogenic endocardium contributes to transient definitive haematopoiesis. Nat Commun 4:1564. doi:10.1038/ncomms 2569

51. Li Z, Lan Y, He W, Chen D, Wang J, Zhou F, Wang Y, Sun H, Chen X, Xu C, Li S, Pang Y, Zhang G, Yang L, Zhu L, Fan M, Shang A, Ju Z, Luo L, Ding Y, Guo W, Yuan W, Yang X, Liu B (2012) Mouse embryonic head as a site for hematopoietic stem cell development. Cell Stem Cell 11(5):663-675. doi:10.1016/j. stem.2012.07.004

52. Bertrand JY, Chi NC, Santoso B, Teng S, Stainier DY, Traver D (2010) Haematopoietic stem cells derive directly from aortic endothelium during development. Nature 464(7285):108-111. doi:10.1038/nature08738

53. Boisset JC, van Cappellen W, Andrieu-Soler C, Galjart N, Dzierzak E, Robin C (2010) In vivo imaging of haematopoietic cells emerging from the mouse aortic endothelium. Nature 464(7285): 116-120. doi:10.1038/nature08764

54. Kissa K, Herbomel P (2010) Blood stem cells emerge from aortic endothelium by a novel type of cell transition. Nature 464(7285):112-115. doi:10.1038/nature08761

55. de Bruijn MF, Ma X, Robin C, Ottersbach K, Sanchez MJ, Dzierzak E (2002) Hematopoietic stem cells localize to the endothelial cell layer in the midgestation mouse aorta. Immunity 16(5):673-683

56. North T, Gu TL, Stacy T, Wang Q, Howard L, Binder M, MarínPadilla M, Speck NA (1999) Cbfa2 is required for the formation of intra-aortic hematopoietic clusters. Development (Cambridge, England) 126(11):2563-2575

57. North TE, de Bruijn MF, Stacy T, Talebian L, Lind E, Robin C, Binder M, Dzierzak E, Speck NA (2002) Runx1 expression marks long-term repopulating hematopoietic stem cells in the midgestation mouse embryo. Immunity 16(5):661-672

58. Chen MJ, Yokomizo T, Zeigler BM, Dzierzak E, Speck NA (2009) Runx1 is required for the endothelial to haematopoietic cell transition but not thereafter. Nature 457(7231):887-891. doi:10.1038/nature07619

59. Swiers G, Baumann C, O'Rourke J, Giannoulatou E, Taylor S, Joshi A, Moignard V, Pina C, Bee T, Kokkaliaris KD, Yoshimoto M, Yoder MC, Frampton J, Schroeder T, Enver T, Gottgens B, de Bruijn MF (2013) Early dynamic fate changes in haemogenic endothelium characterized at the single-cell level. Nat Commun 4:2924. doi:10.1038/ncomms3924

60. Ditadi A, Sturgeon CM, Tober J, Awong G, Kennedy M, Yzaguirre AD, Azzola L, Ng ES, Stanley EG, French DL, Cheng X, Gadue P, Speck NA, Elefanty AG, Keller G (2015) Human definitive haemogenic endothelium and arterial vascular endothelium represent distinct lineages. Nat Cell Biol 17(5):580-591. doi:10.1038/ncb3161

61. Marcelo KL, Sills TM, Coskun S, Vasavada H, Sanglikar S, Goldie LC, Hirschi KK (2013) Hemogenic endothelial cell specification requires c-Kit, Notch signaling, and p27-mediated cell-cycle control. Dev Cell 27(5):504-515. doi:10.1016/j. devcel.2013.11.004

62. Kabrun N, Buhring HJ, Choi K, Ullrich A, Risau W, Keller G (1997) Flk-1 expression defines a population of early embryonic hematopoietic precursors. Development (Cambridge, England) 124(10):2039-2048

63. Nishikawa SI, Nishikawa S, Kawamoto H, Yoshida H, Kizumoto M, Kataoka H, Katsura Y (1998) In vitro generation of lymphohematopoietic cells from endothelial cells purified from murine embryos. Immunity 8(6):761-769

64. Hirai H, Ogawa M, Suzuki N, Yamamoto M, Breier G, Mazda O, Imanishi J, Nishikawa S (2003) Hemogenic and nonhemogenic endothelium can be distinguished by the activity of fetal liver kinase (Flk)-1 promoter/enhancer during mouse embryogenesis. Blood 101(3):886-893. doi:10.1182/blood2002-02-0655

65. Oberlin E, Tavian M, Blazsek I, Peault B (2002) Blood-forming potential of vascular endothelium in the human embryo. Development (Cambridge, England) 129(17):4147-4157

66. Anderson H, Patch TC, Reddy PN, Hagedorn EJ, Kim PG, Soltis KA, Chen MJ, Tamplin OJ, Frye M, MacLean GA, Hubner K, Bauer DE, Kanki JP, Vogin G, Huston NC, Nguyen M, Fujiwara Y, Paw BH, Vestweber D, Zon LI, Orkin SH, Daley GQ, Shah DI (2015) Hematopoietic stem cells develop in the absence of endothelial cadherin 5 expression. Blood. doi:10.1182/blood2015-07-659276

67. Chen Michael J, Li Y, De Obaldia Maria E, Yang Q, Yzaguirre Amanda D, Yamada-Inagawa T, Vink Chris S, Bhandoola A, Dzierzak E, Speck Nancy A (2011) Erythroid/myeloid progenitors and hematopoietic stem cells originate from distinct populations of endothelial cells. Cell Stem Cell 9(6):541-552. doi:10.1016/j.stem.2011.10.003

68. Ogawa M, Kizumoto M, Nishikawa S, Fujimoto T, Kodama H, Nishikawa SI (1999) Expression of alpha4-integrin defines the earliest precursor of hematopoietic cell lineage diverged from endothelial cells. Blood 93(4):1168-1177

69. Eilken HM, Nishikawa S-I, Schroeder T (2009) Continuous single-cell imaging of blood generation from haemogenic endothelium. Nature 457 (7231):896-900. doi:http://www. nature.com/nature/journal/v457/n7231/suppinfo/nature07760_ S1.html

70. Van Handel B, Montel-Hagen A, Sasidharan R, Nakano H, Ferrari R, Boogerd CJ, Schredelseker J, Wang Y, Hunter S, Org T, Zhou J, Li X, Pellegrini M, Chen JN, Orkin SH, Kurdistani SK, Evans SM, Nakano A, Mikkola HK (2012) Scl represses cardiomyogenesis in prospective hemogenic endothelium and endocardium. Cell 150(3):590-605. doi:10.1016/j.cell.2012.06. 026

71. Nadin BM, Goodell MA, Hirschi KK (2003) Phenotype and hematopoietic potential of side population cells throughout embryonic development. Blood 102(7):2436-2443. doi:10.1182/ blood-2003-01-0118

72. Goodell MA, Brose K, Paradis G, Conner AS, Mulligan RC (1996) Isolation and functional properties of murine hematopoietic stem cells that are replicating in vivo. J Exp Med 183(4):1797-1806

73. Bohnsack BL, Lai L, Dolle P, Hirschi KK (2004) Signaling hierarchy downstream of retinoic acid that independently regulates vascular remodeling and endothelial cell proliferation. Genes Dev 18(11):1345-1358. doi:10.1101/gad.1184904

74. Lai L, Bohnsack BL, Niederreither K, Hirschi KK (2003) Retinoic acid regulates endothelial cell proliferation during vasculogenesis. Development (Cambridge, England) 130(26):6465-6474. doi:10.1242/dev.00887

75. Chanda B, Ditadi A, Iscove NN, Keller G (2013) Retinoic acid signaling is essential for embryonic hematopoietic stem cell development. Cell 155(1):215-227. doi:10.1016/j.cell.2013.08. 055

76. Niederreither K, Subbarayan V, Dolle P, Chambon P (1999) Embryonic retinoic acid synthesis is essential for early mouse post-implantation development. Nat Genet 21(4):444-448. doi: $10.1038 / 7788$

77. Makita T, Duncan SA, Sucov HM (2005) Retinoic acid, hypoxia, and GATA factors cooperatively control the onset of 
fetal liver erythropoietin expression and erythropoietic differentiation. Dev Biol 280(1):59-72. doi:10.1016/j.ydbio.2005.01. 001

78. Purton LE, Dworkin S, Olsen GH, Walkley CR, Fabb SA, Collins SJ, Chambon P (2006) RARgamma is critical for maintaining a balance between hematopoietic stem cell selfrenewal and differentiation. J Exp Med 203(5):1283-1293. doi:10.1084/jem.20052105

79. Kumar S, Sandell LL, Trainor PA, Koentgen F, Duester G (2012) Alcohol and aldehyde dehydrogenases: retinoid metabolic effects in mouse knockout models. Biochim Biophys Acta 1821 1:198-205. doi:10.1016/j.bbalip.2011.04.004

80. High FA, Epstein JA (2008) The multifaceted role of Notch in cardiac development and disease. Nat Rev Genet 9(1):49-61

81. Liu ZJ, Xiao M, Balint K, Soma A, Pinnix CC, Capobianco AJ, Velazquez OC, Herlyn M (2006) Inhibition of endothelial cell proliferation by Notch1 signaling is mediated by repressing MAPK and PI3 K/Akt pathways and requires MAML1. FASEB J Off Publ Fed Am Soc Exp Biol 20(7):1009-1011. doi:10.1096/ fj.05-4880fje

82. Uyttendaele H, Marazzi G, Wu G, Yan Q, Sassoon D, Kitajewski J (1996) Notch4/int-3, a mammary proto-oncogene, is an endothelial cell-specific mammalian Notch gene. Development (Cambridge, England) 122(7):2251-2259

83. Limbourg FP, Takeshita K, Radtke F, Bronson RT, Chin MT, Liao JK (2005) Essential role of endothelial Notch1 in angiogenesis. Circulation 111(14):1826-1832. doi:10.1161/01.cir. 0000160870.93058.dd

84. Krebs LT, Xue Y, Norton CR, Shutter JR, Maguire M, Sundberg JP, Gallahan D, Closson V, Kitajewski J, Callahan R, Smith GH, Stark KL, Gridley T (2000) Notch signaling is essential for vascular morphogenesis in mice. Genes Dev 14(11):1343-1352

85. Schwanbeck R, Schroeder T, Henning K, Kohlhof H, Rieber N, Erfurth ML, Just U (2008) Notch signaling in embryonic and adult myelopoiesis. Cells Tissues Organs 188(1-2):91-102. doi:10.1159/000113531

86. Jang IH, Lu YF, Zhao L, Wenzel PL, Kume T, Datta SM, Arora N, Guiu J, Lagha M, Kim PG, Do EK, Kim JH, Schlaeger TM, Zon LI, Bigas A, Burns CE, Daley GQ (2015) Notch1 acts via Foxc2 to promote definitive hematopoiesis via effects on hemogenic endothelium. Blood 125(9):1418-1426. doi:10.1182/ blood-2014-04-568170

87. Kumano K, Chiba S, Kunisato A, Sata M, Saito T, NakagamiYamaguchi E, Yamaguchi T, Masuda S, Shimizu K, Takahashi T, Ogawa S, Hamada Y, Hirai H (2003) Notch1 but not Notch2 is essential for generating hematopoietic stem cells from endothelial cells. Immunity 18(5):699-711

88. Sattler M, Salgia R (2004) Targeting c-Kit mutations: basic science to novel therapies. Leuk Res 28(Suppl 1):S11-S20. doi:10.1016/j.leukres.2003.10.004

89. Chabot B, Stephenson DA, Chapman VM, Besmer P, Bernstein A (1988) The proto-oncogene c-kit encoding a transmembrane tyrosine kinase receptor maps to the mouse W locus. Nature 335(6185):88-89. doi:10.1038/335088a0

90. Pauklin S, Vallier L (2013) The cell-cycle state of stem cells determines cell fate propensity. Cell 155(1):135-147. doi:10. 1016/j.cell.2013.08.031

91. Hindley C, Philpott A (2013) The cell cycle and pluripotency. Biochem J 451(2):135-143. doi:10.1042/bj20121627

92. Kueh HY, Champhekar A, Nutt SL, Elowitz MB, Rothenberg EV (2013) Positive feedback between PU.1 and the cell cycle controls myeloid differentiation. Science (New York, NY) 341(6146):670-673. doi:10.1126/science.1240831

93. Aggarwal R, Lu J, Pompili VJ, Das H (2012) Hematopoietic stem cells: transcriptional regulation, ex vivo expansion and clinical application. Curr Mol Med 12(1):34-49
94. Li H, Collado M, Villasante A, Matheu A, Lynch CJ, Canamero M, Rizzoti K, Carneiro C, Martinez G, Vidal A, Lovell-Badge R, Serrano M (2012) p27(Kip1) directly represses Sox2 during embryonic stem cell differentiation. Cell Stem Cell 11(6):845-852. doi:10.1016/j.stem.2012.09.014

95. Ciau-Uitz A, Walmsley M, Patient R (2000) Distinct origins of adult and embryonic blood in Xenopus. Cell 102(6):787-796

96. Yokomizo T, Dzierzak E (2010) Three-dimensional cartography of hematopoietic clusters in the vasculature of whole mouse embryos. Development (Cambridge, England) 137(21):36513661. doi:10.1242/dev.051094

97. Jaffredo T, Gautier R, Brajeul V, Dieterlen-Lievre F (2000) Tracing the progeny of the aortic hemangioblast in the avian embryo. Dev Biol 224(2):204-214. doi:10.1006/dbio.2000.9799

98. Tavian M, Hallais MF, Peault B (1999) Emergence of intraembryonic hematopoietic precursors in the pre-liver human embryo. Development (Cambridge, England) 126(4):793-803

99. Taoudi S, Medvinsky A (2007) Functional identification of the hematopoietic stem cell niche in the ventral domain of the embryonic dorsal aorta. Proc Natl Acad Sci USA 104(22):9399-9403. doi:10.1073/pnas.0700984104

100. Smith RA, Glomski CA (1982) "Hemogenic endothelium" of the embryonic aorta: does it exist? Dev Comp Immunol 6(2):359-368

101. Tavian M, Coulombel L, Luton D, Clemente HS, DieterlenLievre F, Peault B (1996) Aorta-associated CD34+ hematopoietic cells in the early human embryo. Blood 87(1):67-72

102. Boisset JC, Clapes T, Klaus A, Papazian N, Onderwater J, Mommaas-Kienhuis M, Cupedo T, Robin C (2015) Progressive maturation toward hematopoietic stem cells in the mouse embryo aorta. Blood 125(3):465-469. doi:10.1182/blood-201407-588954

103. Medvinsky A, Rybtsov S, Taoudi S (2011) Embryonic origin of the adult hematopoietic system: advances and questions. Development (Cambridge, England) 138 (6):1017-1031. doi:10. 1242/dev.040998

104. Sanchez MJ, Holmes A, Miles C, Dzierzak E (1996) Characterization of the first definitive hematopoietic stem cells in the AGM and liver of the mouse embryo. Immunity 5(6):513-525

105. Taoudi S, Morrison AM, Inoue H, Gribi R, Ure J, Medvinsky A (2005) Progressive divergence of definitive haematopoietic stem cells from the endothelial compartment does not depend on contact with the foetal liver. Development Cambridge, England) 132(18):4179-4191. doi:10.1242/dev.01974

106. Taoudi S, Gonneau C, Moore K, Sheridan JM, Blackburn CC, Taylor E, Medvinsky A (2008) Extensive hematopoietic stem cell generation in the AGM region via maturation of VE-cadherin +CD45 + pre-definitive HSCs. Cell Stem Cell 3(1):99-108. doi:10.1016/j.stem.2008.06.004

107. Mizuochi C, Fraser ST, Biasch K, Horio Y, Kikushige Y, Tani K, Akashi K, Tavian M, Sugiyama D (2012) Intra-aortic clusters undergo endothelial to hematopoietic phenotypic transition during early embryogenesis. PLoS ONE 7(4):e35763. doi:10. 1371/journal.pone.0035763

108. Rybtsov S, Sobiesiak M, Taoudi S, Souilhol C, Senserrich J, Liakhovitskaia A, Ivanovs A, Frampton J, Zhao S, Medvinsky A (2011) Hierarchical organization and early hematopoietic specification of the developing HSC lineage in the AGM region. J Exp Med 208(6):1305-1315. doi:10.1084/jem.20102419

109. Pouget C, Gautier R, Teillet M-A, Jaffredo T (2006) Somitederived cells replace ventral aortic hemangioblasts and provide aortic smooth muscle cells of the trunk. Development (Cambridge, England) 133(6):1013-1022. doi:10.1242/dev.02269

110. Esner M, Meilhac SM, Relaix F, Nicolas JF, Cossu G, Buckingham ME (2006) Smooth muscle of the dorsal aorta shares a common clonal origin with skeletal muscle of the myotome. 
Development (Cambridge, England) 133(4):737-749. doi:10. 1242/dev.02226

111. Pardanaud L, Dieterlen-Lievre F (1999) Manipulation of the angiopoietic/hemangiopoietic commitment in the avian embryo. Development (Cambridge, England) 126(4):617-627

112. Peeters M, Ottersbach K, Bollerot K, Orelio C, de Bruijn M, Wijgerde M, Dzierzak E (2009) Ventral embryonic tissues and Hedgehog proteins induce early AGM hematopoietic stem cell development. Development (Cambridge, England) 136(15):2613-2621. doi:10.1242/dev.034728

113. Mascarenhas MI, Parker A, Dzierzak E, Ottersbach K (2009) Identification of novel regulators of hematopoietic stem cell development through refinement of stem cell localization and expression profiling. Blood 114(21):4645-4653. doi:10.1182/ blood-2009-06-230037

114. Marshall CJ, Kinnon C, Thrasher AJ (2000) Polarized expression of bone morphogenetic protein- 4 in the human aorta-gonadmesonephros region. Blood 96(4):1591-1593

115. Oostendorp RA, Harvey KN, Kusadasi N, de Bruijn MF, Saris C, Ploemacher RE, Medvinsky AL, Dzierzak EA (2002) Stromal cell lines from mouse aorta-gonads-mesonephros subregions are potent supporters of hematopoietic stem cell activity. Blood 99(4):1183-1189

116. Mirshekar-Syahkal B, Haak E, Kimber GM, van Leusden K, Harvey K, O'Rourke J, Laborda J, Bauer SR, de Bruijn MF, Ferguson-Smith AC, Dzierzak E, Ottersbach K (2013) Dlk1 is a negative regulator of emerging hematopoietic stem and progenitor cells. Haematologica 98(2):163-171. doi:10.3324/ haematol.2012.070789

117. Richard C, Drevon C, Canto PY, Villain G, Bollerot K, Lempereur A, Teillet MA, Vincent C, Rossello Castillo C, Torres M, Piwarzyk E, Speck NA, Souyri M, Jaffredo T (2013) Endothelio-mesenchymal interaction controls runx1 expression and modulates the notch pathway to initiate aortic hematopoiesis. Dev Cell 24(6):600-611. doi:10.1016/j.devcel.2013.02.011

118. Adamo L, Naveiras O, Wenzel PL, McKinney-Freeman S, Mack PJ, Gracia-Sancho J, Suchy-Dicey A, Yoshimoto M, Lensch MW, Yoder MC, Garcia-Cardena G, Daley GQ (2009) Biomechanical forces promote embryonic haematopoiesis. Nature 459(7250):1131-1135. doi:http://www.nature.com/nature/journal/ v459/n7250/suppinfo/nature08073_S1.html

119. North TE, Goessling W, Peeters M, Li P, Ceol C, Lord AM, Weber GJ, Harris J, Cutting CC, Huang P, Dzierzak E, Zon LI (2009) Hematopoietic stem cell development is dependent on blood flow. Cell 137(4):736-748. doi:10.1016/j.cell.2009.04.023

120. Swiers G, Rode C, Azzoni E, de Bruijn MF (2013) A short history of hemogenic endothelium. Blood Cells Mol Dis 51(4):206-212. doi:10.1016/j.bcmd.2013.09.005

121. Lacaud G, Gore L, Kennedy M, Kouskoff V, Kingsley P, Hogan C, Carlsson L, Speck N, Palis J, Keller G (2002) Runx1 is essential for hematopoietic commitment at the hemangioblast stage of development in vitro. Blood 100(2):458-466. doi:10. 1182/blood-2001-12-0321

122. Yokomizo T, Ogawa M, Osato M, Kanno T, Yoshida H, Fujimoto T, Fraser S, Nishikawa S, Okada H, Satake M, Noda T, Nishikawa S, Ito Y (2001) Requirement of Runx1/AML1/ PEBP2alphaB for the generation of haematopoietic cells from endothelial cells. Genes Cells Devoted Mol Cell Mech 6(1):13-23

123. Swiers G, de Bruijn M, Speck NA (2010) Hematopoietic stem cell emergence in the conceptus and the role of Runx1. Int J Dev Biol 54(6-7):1151-1163. doi:10.1387/ijdb.103106gs

124. Cai Z, de Bruijn M, Ma X, Dortland B, Luteijn T, Downing RJ, Dzierzak E (2000) Haploinsufficiency of AML1 affects the temporal and spatial generation of hematopoietic stem cells in the mouse embryo. Immunity 13(4):423-431
125. Okuda T, van Deursen J, Hiebert SW, Grosveld G, Downing JR (1996) AML1, the target of multiple chromosomal translocations in human leukemia, is essential for normal fetal liver hematopoiesis. Cell 84(2):321-330

126. Wang Q, Stacy T, Miller JD, Lewis AF, Gu TL, Huang X, Bushweller JH, Bories JC, Alt FW, Ryan G, Liu PP, WynshawBoris A, Binder M, Marin-Padilla M, Sharpe AH, Speck NA (1996) The CBFbeta subunit is essential for CBFalpha2 (AML1) function in vivo. Cell 87(4):697-708

127. Liakhovitskaia A, Rybtsov S, Smith T, Batsivari A, Rybtsova N, Rode C, de Bruijn M, Buchholz F, Gordon-Keylock S, Zhao S, Medvinsky A (2014) Runx1 is required for progression of CD41+ embryonic precursors into HSCs but not prior to this. Development (Cambridge, England) 141(17):3319-3323. doi:10.1242/dev.110841

128. Huang G, Zhang P, Hirai H, Elf S, Yan X, Chen Z, Koschmieder S, Okuno Y, Dayaram T, Growney JD, Shivdasani RA, Gilliland DG, Speck NA, Nimer SD, Tenen DG (2008) PU.1 is a major downstream target of AML1 (RUNX1) in adult mouse hematopoiesis. Nat Genet 40(1):51-60. doi:10.1038/ng.2007.7

129. Gottgens B, Nastos A, Kinston S, Piltz S, Delabesse EC, Stanley M, Sanchez MJ, Ciau-Uitz A, Patient R, Green AR (2002) Establishing the transcriptional programme for blood: the SCL stem cell enhancer is regulated by a multiprotein complex containing Ets and GATA factors. EMBO J 21(12):3039-3050. doi:10.1093/emboj/cdf286

130. Nottingham WT, Jarratt A, Burgess M, Speck CL, Cheng JF, Prabhakar S, Rubin EM, Li PS, Sloane-Stanley J, Kong ASJ, de Bruijn MF (2007) Runx1-mediated hematopoietic stem-cell emergence is controlled by a Gata/Ets/SCL-regulated enhancer. Blood 110(13):4188-4197. doi:10.1182/blood-2007-07-100883

131. Lizama CO, Hawkins JS, Schmitt CE, Bos FL, Zape JP, Cautivo KM, Borges Pinto H, Rhyner AM, Yu H, Donohoe ME, Wythe JD, Zovein AC (2015) Repression of arterial genes in hemogenic endothelium is sufficient for haematopoietic fate acquisition. Nat Commun 6:7739. doi:10.1038/ncomms8739

132. Ghozi MC, Bernstein Y, Negreanu V, Levanon D, Groner Y (1996) Expression of the human acute myeloid leukemia gene AML1 is regulated by two promoter regions. Proc Natl Acad Sci USA 93(5):1935-1940

133. Lie ALM, Marinopoulou E, Li Y, Patel R, Stefanska M, Bonifer C, Miller C, Kouskoff V, Lacaud G (2014) RUNX1 positively regulates a cell adhesion and migration program in murine hemogenic endothelium prior to blood emergence. 124 (11):e11-20. doi:10.1182/blood-2014-04-572958

134. Sroczynska P, Lancrin C, Kouskoff V, Lacaud G (2009) The differential activities of Runx 1 promoters define milestones during embryonic hematopoiesis. Blood 114(26):5279-5289. doi:10.1182/blood-2009-05-222307

135. Telfer JC, Rothenberg EV (2001) Expression and function of a stem cell promoter for the murine CBFalpha2 gene: distinct roles and regulation in natural killer and $\mathrm{T}$ cell development. Dev Biol 229(2):363-382. doi:10.1006/dbio.2000.9991

136. Bee T, Ashley EL, Bickley SR, Jarratt A, Li PS, Sloane-Stanley J, Gottgens B, de Bruijn MF (2009) The mouse Runx1 +23 hematopoietic stem cell enhancer confers hematopoietic specificity to both Runx1 promoters. Blood 113(21):5121-5124. doi:10.1182/blood-2008-12-193003

137. Lancrin C, Mazan M, Stefanska M, Patel R, Lichtinger M, Costa G, Vargel Ö, Wilson NK, Möröy T, Bonifer C, Göttgens B, Kouskoff V, Lacaud G (2012) GFI1 and GFI1B control the loss of endothelial identity of hemogenic endothelium during hematopoietic commitment, vol 120. vol 2. doi:10.1182/blood2011-10-386094

138. Lam EY, Chau JY, Kalev-Zylinska ML, Fountaine TM, Mead RS, Hall CJ, Crosier PS, Crosier KE, Flores MV (2009) 
Zebrafish runx1 promoter-EGFP transgenics mark discrete sites of definitive blood progenitors. Blood 113(6):1241-1249. doi:10.1182/blood-2008-04-149898

139. Challen GA, Goodell MA (2010) Runx1 isoforms show differential expression patterns during hematopoietic development but have similar functional effects in adult hematopoietic stem cells. Exp Hematol 38(5):403-416. doi:10.1016/j.exphem.2010.02.011

140. Tanaka Y, Joshi A, Wilson NK, Kinston S, Nishikawa S, Gottgens B (2012) The transcriptional programme controlled by Runx1 during early embryonic blood development. Dev Biol 366(2):404-419. doi:10.1016/j.ydbio.2012.03.024

141. Tober J, Yzaguirre AD, Piwarzyk E, Speck NA (2013) Distinct temporal requirements for Runx1 in hematopoietic progenitors and stem cells. Development (Cambridge, England) 140(18):3765-3776. doi:10.1242/dev.094961

142. Liakhovitskaia A, Gribi R, Stamateris E, Villain G, Jaffredo T, Wilkie R, Gilchrist D, Yang J, Ure J, Medvinsky A (2009) Restoration of Runx1 expression in the Tie2 cell compartment rescues definitive hematopoietic stem cells and extends life of Runx1 knockout animals until birth. Stem Cells (Dayton, Ohio) 27(7):1616-1624. doi:10.1002/stem.71

143. Growney JD, Shigematsu H, Li Z, Lee BH, Adelsperger J, Rowan R, Curley DP, Kutok JL, Akashi K, Williams IR, Speck NA, Gilliland DG (2005) Loss of Runx1 perturbs adult hematopoiesis and is associated with a myeloproliferative phenotype. Blood 106(2):494-504. doi:10.1182/blood-2004-08-3280

144. Drevon C, Jaffredo T (2014) Cell interactions and cell signaling during hematopoietic development. Exp Cell Res 329(2):200-206. doi:10.1016/j.yexcr.2014.10.009

145. Robin C, Ottersbach K, Durand C, Peeters M, Vanes L, Tybulewicz V, Dzierzak E (2006) An unexpected role for IL-3 in the embryonic development of hematopoietic stem cells. Dev Cell 11(2):171-180. doi:10.1016/j.devcel.2006.07.002

146. Tijssen MR, Cvejic A, Joshi A, Hannah RL, Ferreira R, Forrai A, Bellissimo DC, Oram SH, Smethurst PA, Wilson NK, Wang X, Ottersbach K, Stemple DL, Green AR, Ouwehand WH, Gottgens B (2011) Genome-wide analysis of simultaneous GATA1/2, RUNX1, FLI1, and SCL binding in megakaryocytes identifies hematopoietic regulators. Dev Cell 20(5):597-609. doi:10.1016/j.devcel.2011.04.008

147. Patterson LJ, Gering M, Patient R (2005) Scl is required for dorsal aorta as well as blood formation in zebrafish embryos. Blood 105(9):3502-3511. doi:10.1182/blood-2004-09-3547

148. Ciau-Uitz A, Monteiro R, Kirmizitas A, Patient R (2014) Developmental hematopoiesis: ontogeny, genetic programming and conservation. Exp Hematol 42(8):669-683. doi:10.1016/j. exphem.2014.06.001

149. Robb L, Lyons I, Li R, Hartley L, Kontgen F, Harvey RP, Metcalf D, Begley CG (1995) Absence of yolk sac hematopoiesis from mice with a targeted disruption of the scl gene. Proc Natl Acad Sci USA 92(15):7075-7079

150. Warren AJ, Colledge WH, Carlton MB, Evans MJ, Smith AJ, Rabbitts TH (1994) The oncogenic cysteine-rich LIM domain protein rbtn2 is essential for erythroid development. Cell 78(1):45-57

151. Tsai FY, Keller G, Kuo FC, Weiss M, Chen J, Rosenblatt M, Alt FW, Orkin SH (1994) An early haematopoietic defect in mice lacking the transcription factor GATA-2. Nature 371(6494):221-226. doi:10.1038/371221a0

152. Pevny L, Simon MC, Robertson E, Klein WH, Tsai SF, D'Agati V, Orkin SH, Costantini F (1991) Erythroid differentiation in chimaeric mice blocked by a targeted mutation in the gene for transcription factor GATA-1. Nature 349(6306):257-260. doi: $10.1038 / 349257 \mathrm{a} 0$

153. Zhen F, Lan Y, Yan B, Zhang W, Wen Z (2013) Hemogenic endothelium specification and hematopoietic stem cell maintenance employ distinct $\mathrm{Scl}$ isoforms. Development (Cambridge, England) 140(19):3977-3985. doi:10.1242/dev. 097071

154. Minegishi N, Ohta J, Yamagiwa H, Suzuki N, Kawauchi S, Zhou Y, Takahashi S, Hayashi N, Engel JD, Yamamoto M (1999) The mouse GATA-2 gene is expressed in the para-aortic splanchnopleura and aorta-gonads and mesonephros region. Blood 93(12):4196-4207

155. Ling KW, Ottersbach K, van Hamburg JP, Oziemlak A, Tsai FY, Orkin SH, Ploemacher R, Hendriks RW, Dzierzak E (2004) GATA-2 plays two functionally distinct roles during the ontogeny of hematopoietic stem cells. J Exp Med 200(7):871-882. doi:10.1084/jem.20031556

156. Gao X, Johnson KD, Chang YI, Boyer ME, Dewey CN, Zhang J, Bresnick EH (2013) Gata2 cis-element is required for hematopoietic stem cell generation in the mammalian embryo. J Exp Med 210(13):2833-2842. doi:10.1084/jem.20130733

157. de Pater E, Kaimakis P, Vink CS, Yokomizo T, Yamada-Inagawa T, van der Linden R, Kartalaei PS, Camper SA, Speck N, Dzierzak E (2013) Gata2 is required for HSC generation and survival. J Exp Med 210(13):2843-2850. doi:10.1084/jem. 20130751

158. Yamada Y, Warren AJ, Dobson C, Forster A, Pannell R, Rabbitts TH (1998) The T cell leukemia LIM protein Lmo2 is necessary for adult mouse hematopoiesis. Proc Natl Acad Sci USA 95(7):3890-3895

159. Yamada Y, Pannell R, Forster A, Rabbitts TH (2000) The oncogenic LIM-only transcription factor $\mathrm{Lmo} 2$ regulates angiogenesis but not vasculogenesis in mice. Proc Natl Acad Sci USA 97(1):320-324

160. Patterson LJ, Gering M, Eckfeldt CE, Green AR, Verfaillie CM, Ekker SC, Patient R (2007) The transcription factors Scl and Lmo2 act together during development of the hemangioblast in zebrafish. Blood 109(6):2389-2398. doi:10.1182/blood-200602-003087

161. Bigas A, Robert-Moreno A, Espinosa L (2010) The Notch pathway in the developing hematopoietic system. Int J Dev Biol 54(6-7):1175-1188. doi:10.1387/ijdb.093049ab

162. Hadland BK, Huppert SS, Kanungo J, Xue Y, Jiang R, Gridley T, Conlon RA, Cheng AM, Kopan R, Longmore GD (2004) A requirement for Notch1 distinguishes 2 phases of definitive hematopoiesis during development. Blood 104(10):3097-3105. doi:10.1182/blood-2004-03-1224

163. Hadland BK, Varnum-Finney B, Poulos MG, Moon RT, Butler JM, Rafii S, Bernstein ID (2015) Endothelium and NOTCH specify and amplify aorta-gonad-mesonephros-derived hematopoietic stem cells. J Clin Investig 125(5):2032-2045. doi:10.1172/jci80137

164. Bigas A, D'Altri T, Espinosa L (2012) The Notch pathway in hematopoietic stem cells. Curr Top Microbiol Immunol 360:1-18. doi:10.1007/82_2012_229

165. Bigas A, Guiu J, Gama-Norton L (2013) Notch and Wnt signaling in the emergence of hematopoietic stem cells. Blood Cells Mol Dis 51(4):264-270. doi:10.1016/j.bcmd.2013.07.005

166. Robert-Moreno A, Espinosa L, de la Pompa JL, Bigas A (2005) RBPjkappa-dependent Notch function regulates Gata2 and is essential for the formation of intra-embryonic hematopoietic cells. Development (Cambridge, England) 132(5):1117-1126. doi: $10.1242 /$ dev. 01660

167. Robert Moreno À, Guiu J, Ruiz Herguido C, López ME, Inglés Esteve J, Riera L, Tipping A, Enver T, Dzierzak E, Gridley T, Espinosa L, Bigas A (2008) Impaired embryonic haematopoiesis yet normal arterial development in the absence of the Notch ligand Jagged1, vol 27. vol 13. doi:10.1038/emboj.2008.113

168. Guiu J, Shimizu R, D’Altri T, Fraser ST, Hatakeyama J, Bresnick EH, Kageyama R, Dzierzak E, Yamamoto M, Espinosa L, 
Bigas A (2013) Hes repressors are essential regulators of hematopoietic stem cell development downstream of Notch signaling. J Exp Med 210(1):71-84. doi:10.1084/jem.20120993

169. Oka C, Nakano T, Wakeham A, de la Pompa JL, Mori C, Sakai T, Okazaki S, Kawaichi M, Shiota K, Mak TW, Honjo T (1995) Disruption of the mouse RBP-J kappa gene results in early embryonic death. Development (Cambridge, England) 121(10):3291-3301

170. Butko E, Distel M, Pouget C, Weijts B, Kobayashi I, Ng K, Mosimann C, Poulain FE, McPherson A, Ni CW, Stachura DL, Del Cid N, Espin-Palazon R, Lawson ND, Dorsky R, Clements WK, Traver D (2015) Gata2b is a restricted early regulator of hemogenic endothelium in the zebrafish embryo. Development (Cambridge, England) 142(6):1050-1061. doi:10.1242/dev. 119180

171. Van de Walle I, Waegemans E, De Medts J, De Smet G, De Smedt M, Snauwaert S, Vandekerckhove B, Kerre T, Leclercq G, Plum J, Gridley T, Wang T, Koch U, Radtke F, Taghon T (2013) Specific Notch receptor-ligand interactions control human TCR-alphabeta/gammadelta development by inducing differential Notch signal strength. J Exp Med 210(4):683-697. doi:10.1084/jem.20121798

172. Petrovic J, Formosa-Jordan P, Luna-Escalante JC, Abello G, Ibanes M, Neves J, Giraldez F (2014) Ligand-dependent Notch signaling strength orchestrates lateral induction and lateral inhibition in the developing inner ear. Development (Cambridge, England) 141(11):2313-2324. doi:10.1242/dev.108100

173. Gama-Norton L, Ferrando E, Ruiz-Herguido C, Liu Z, Guiu J, Islam AB, Lee SU, Yan M, Guidos CJ, Lopez-Bigas N, Maeda T, Espinosa L, Kopan R, Bigas A (2015) Notch signal strength controls cell fate in the haemogenic endothelium. Nat Commun 6:8510. doi: $10.1038 /$ ncomms 9510

174. Ayllon V, Bueno C, Ramos-Mejia V, Navarro-Montero O, Prieto C, Real PJ, Romero T, Garcia-Leon MJ, Toribio ML, Bigas A, Menendez P (2015) The Notch ligand DLL4 specifically marks human hematoendothelial progenitors and regulates their hematopoietic fate. Leukemia. doi:10.1038/leu.2015.74

175. Guiu J, Bergen DJ, De Pater E, Islam AB, Ayllon V, GamaNorton L, Ruiz-Herguido C, Gonzalez J, Lopez-Bigas N, Menendez P, Dzierzak E, Espinosa L, Bigas A (2014) Identification of $\mathrm{Cdca} 7$ as a novel Notch transcriptional target involved in hematopoietic stem cell emergence. J Exp Med 211(12):2411-2423. doi:10.1084/jem.20131857

176. Ruiz-Herguido C, Guiu J, D'Altri T, Ingles-Esteve J, Dzierzak E, Espinosa L, Bigas A (2012) Hematopoietic stem cell development requires transient Wnt/beta-catenin activity. J Exp Med 209(8):1457-1468. doi:10.1084/jem.20120225

177. Goessling W, North TE, Loewer S, Lord AM, Lee S, StoickCooper CL, Weidinger G, Puder M, Daley GQ, Moon RT, Zon LI (2009) Genetic interaction of PGE2 and Wnt signaling regulates developmental specification of stem cells and regeneration. Cell 136(6):1136-1147. doi:10.1016/j.cell.2009.01.015

178. Sturgeon CM, Ditadi A, Awong G, Kennedy M, Keller G (2014) Wnt signaling controls the specification of definitive and primitive hematopoiesis from human pluripotent stem cells. Nat Biotechnol 32(6):554-561. doi:10.1038/nbt.2915

179. Ivanova NB, Dimos JT, Schaniel C, Hackney JA, Moore KA, Lemischka IR (2002) A stem cell molecular signature. Science (New York, NY) 298(5593):601-604. doi:10.1126/science. 1073823

180. Taghon T, Thys K, De Smedt M, Weerkamp F, Staal FJ, Plum J, Leclercq G (2003) Homeobox gene expression profile in human hematopoietic multipotent stem cells and T-cell progenitors: implications for human T-cell development. Leukemia 17(6):1157-1163. doi:10.1038/sj.leu.2402947
181. Forsberg EC, Prohaska SS, Katzman S, Heffner GC, Stuart JM, Weissman IL (2005) Differential expression of novel potential regulators in hematopoietic stem cells. PLoS Genet 1(3):e28. doi:10.1371/journal.pgen.0010028

182. Sauvageau G, Lansdorp PM, Eaves CJ, Hogge DE, Dragowska WH, Reid DS, Largman C, Lawrence HJ, Humphries RK (1994) Differential expression of homeobox genes in functionally distinct CD34+ subpopulations of human bone marrow cells. Proc Natl Acad Sci USA 91(25):12223-12227

183. Iacovino M, Chong D, Szatmari I, Hartweck L, Rux D, Caprioli A, Cleaver O, Kyba M (2011) HoxA3 is an apical regulator of haemogenic endothelium. Nat Cell Biol 13(1):72-78. doi:10. 1038/ncb2137

184. Kyba M, Perlingeiro RC, Daley GQ (2002) HoxB4 confers definitive lymphoid-myeloid engraftment potential on embryonic stem cell and yolk sac hematopoietic progenitors. Cell 109(1):29-37

185. Oshima M, Endoh M, Endo TA, Toyoda T, Nakajima-Takagi Y, Sugiyama F, Koseki H, Kyba M, Iwama A, Osawa M (2011) Genome-wide analysis of target genes regulated by HoxB4 in hematopoietic stem and progenitor cells developing from embryonic stem cells. Blood 117(15):e142-e150. doi:10.1182/ blood-2010-12-323212

186. Corada M, Orsenigo F, Morini MF, Pitulescu ME, Bhat G, Nyquist $\mathrm{D}$, Breviario $\mathrm{F}$, Conti $\mathrm{V}$, Briot $\mathrm{A}$, Iruela-Arispe ML, Adams RH, Dejana E (2013) Sox17 is indispensable for acquisition and maintenance of arterial identity. Nature communications 4:2609. doi:10.1038/ncomms3609

187. Clarke RL, Yzaguirre AD, Yashiro-Ohtani Y, Bondue A, Blanpain C, Pear WS, Speck NA, Keller G (2013) The expression of Sox17 identifies and regulates haemogenic endothelium. Nat Cell Biol 15(5):502-510. doi:10.1038/ ncb2724

188. He S, Kim I, Lim MS, Morrison SJ (2011) Sox17 expression confers self-renewal potential and fetal stem cell characteristics upon adult hematopoietic progenitors. Genes Dev 25(15):1613-1627. doi:10.1101/gad.2052911

189. Nakajima-Takagi Y, Osawa M, Oshima M, Takagi H, Miyagi S, Endoh M, Endo TA, Takayama N, Eto K, Toyoda T, Koseki H, Nakauchi H, Iwama A (2013) Role of SOX17 in hematopoietic development from human embryonic stem cells, vol 121. vol 3. doi:10.1182/blood-2012-05-431403

190. Bos FL, Hawkins JS, Zovein AC (2015) Single-cell resolution of morphological changes in hemogenic endothelium. Development (Cambridge, England) 142 (15):2719-2724. doi:10.1242/ dev. 121350

191. Clarke RL, Robitaille AM, Moon RT, Keller G (2015) A Quantitative proteomic analysis of hemogenic endothelium reveals differential regulation of hematopoiesis by SOX17. Stem cell Rep 5(2):291-304. doi:10.1016/j.stemcr.2015.07.008

192. Gandillet A, Serrano AG, Pearson S, Lie ALM, Lacaud G, Kouskoff V (2009) Sox7-sustained expression alters the balance between proliferation and differentiation of hematopoietic progenitors at the onset of blood specification. Blood 114(23):4813-4822. doi:10.1182/blood-2009-06-226290

193. Serrano AG, Gandillet A, Pearson S, Lacaud G, Kouskoff V (2010) Contrasting effects of Sox17- and Sox18-sustained expression at the onset of blood specification, vol 115. vol 19 . doi:10.1182/blood-2009-10-247395

194. Zhang Y, Jin H, Li L, Qin FX, Wen Z (2011) cMyb regulates hematopoietic stem/progenitor cell mobilization during zebrafish hematopoiesis. Blood 118(15):4093-4101. doi:10.1182/ blood-2011-03-342501

195. Mucenski ML, McLain K, Kier AB, Swerdlow SH, Schreiner CM, Miller TA, Pietryga DW, Scott WJ Jr, Potter SS (1991) A 
functional c-myb gene is required for normal murine fetal hepatic hematopoiesis. Cell 65(4):677-689

196. Takakura N, Watanabe T, Suenobu S, Yamada Y, Noda T, Ito Y, Satake M, Suda T (2000) A role for hematopoietic stem cells in promoting angiogenesis. Cell 102(2):199-209

197. Soza-Ried C, Hess I, Netuschil N, Schorpp M, Boehm T (2010) Essential role of c-myb in definitive hematopoiesis is evolutionarily conserved. Proc Natl Acad Sci USA 107(40):17304-17308. doi:10.1073/pnas.1004640107

198. Moriyama A, Inohaya K, Maruyama K, Kudo A (2010) Bef medaka mutant reveals the essential role of c-myb in both primitive and definitive hematopoiesis. Dev Biol 345(2):133-143. doi:10.1016/j.ydbio.2010.06.031

199. Solaimani Kartalaei P, Yamada-Inagawa T, Vink CS, de Pater E, van der Linden R, Marks-Bluth J, van der Sloot A, van den Hout M, Yokomizo T, van Schaick-Solerno ML, Delwel R, Pimanda JE, van IWF, Dzierzak E (2015) Whole-transcriptome analysis of endothelial to hematopoietic stem cell transition reveals a requirement for Gpr56 in HSC generation. The Journal of experimental medicine 212 (1):93-106. doi:10.1084/jem. 20140767

200. Wilson NK, Foster SD, Wang X, Knezevic K, Schütte J, Kaimakis P, Chilarska PM, Kinston S, Ouwehand WH, Dzierzak E, Pimanda JE, de Bruijn MFTR, Göttgens B (2010) Combinatorial transcriptional control in blood stem/progenitor cells: genomewide analysis of ten major transcriptional regulators. Cell Stem Cell 7(4):532-544. doi:10.1016/j.stem.2010.07.016

201. Zhang P, He Q, Chen D, Liu W, Wang L, Zhang C, Ma D, Li W, Liu B, Liu F (2015) G protein-coupled receptor 183 facilitates endothelial-to-hematopoietic transition via Notch1 inhibition. Cell Res 25(10):1093-1107. doi:10.1038/cr.2015.109

202. Jing L, Tamplin OJ, Chen MJ, Deng Q, Patterson S, Kim PG, Durand EM, McNeil A, Green JM, Matsuura S, Ablain J, Brandt MK, Schlaeger TM, Huttenlocher A, Daley GQ, Ravid K, Zon LI (2015) Adenosine signaling promotes hematopoietic stem and progenitor cell emergence. J Exp Med 212(5):649-663. doi:10.1084/jem.20141528

203. Hermouet S, Corre I, Lippert E (2000) Interleukin-8 and other agonists of Gi2 proteins: autocrine paracrine growth factors for human hematopoietic progenitors acting in synergy with colony stimulating factors. Leuk Lymphoma 38(1-2):39-48. doi:10. 3109/10428190009060317

204. Majumder A, Syed KM, Joseph S, Scambler PJ, Dutta D (2015) Histone chaperone HIRA in regulation of transcription factor RUNX1. J Biol Chem 290(21):13053-13063. doi:10.1074/jbc. M114.615492

205. Ramalho-Santos M, Yoon S, Matsuzaki Y, Mulligan RC, Melton DA (2002) "Stemness": transcriptional profiling of embryonic and adult stem cells. Science (New York, NY) 298(5593):597-600. doi:10.1126/science.1072530

206. Grskovic M, Chaivorapol C, Gaspar-Maia A, Li H, RamalhoSantos M (2007) Systematic identification of cis-regulatory sequences active in mouse and human embryonic stem cells. PLoS Genet 3(8):e145. doi:10.1371/journal.pgen.0030145

207. Koh FM, Lizama CO, Wong P, Hawkins JS, Zovein AC (2015) Emergence of hematopoietic stem and progenitor cells involves a Chd1-dependent increase in total nascent transcription. 112 (14):E1734-1743. doi:10.1073/pnas.1424850112

208. Imanirad P, Solaimani Kartalaei P, Crisan M, Vink C, YamadaInagawa T, de Pater E, Kurek D, Kaimakis P, van der Linden R, Speck N, Dzierzak E (2014) HIF1alpha is a regulator of hematopoietic progenitor and stem cell development in hypoxic sites of the mouse embryo. Stem cell research 12(1):24-35. doi:10.1016/j.scr.2013.09.006

209. He Q, Zhang C, Wang L, Zhang P, Ma D, Lv J, Liu F (2015) Inflammatory signaling regulates hematopoietic stem and progenitor cell emergence in vertebrates. Blood 125(7):1098-1106. doi:10.1182/blood-2014-09-601542

210. Sawamiphak S, Kontarakis Z, Stainier DY (2014) Interferon gamma signaling positively regulates hematopoietic stem cell emergence. Dev Cell 31(5):640-653. doi:10.1016/j.devcel.2014. 11.007

211. Li Y, Esain V, Teng L, Xu J, Kwan W, Frost IM, Yzaguirre AD, Cai X, Cortes M, Maijenburg MW, Tober J, Dzierzak E, Orkin SH, Tan K, North TE, Speck NA (2014) Inflammatory signaling regulates embryonic hematopoietic stem and progenitor cell production. Genes Dev 28(23):2597-2612. doi:10.1101/gad. 253302.114

212. Espin-Palazon R, Stachura DL, Campbell CA, Garcia-Moreno D, Del Cid N, Kim AD, Candel S, Meseguer J, Mulero V, Traver D (2014) Proinflammatory signaling regulates hematopoietic stem cell emergence. Cell 159(5):1070-1085. doi:10.1016/j.cell. 2014.10.031

213. Dieterlen-Lievre F, Jaffredo T (2009) Decoding the hemogenic endothelium in mammals. Cell Stem Cell 4(3):189-190. doi:10. 1016/j.stem.2009.02.006

214. Pelosi E, Castelli G, Martin-Padura I, Bordoni V, Santoro S, Conigliaro A, Cerio AM, De Santis Puzzonia M, Marighetti P, Biffoni M, Alonzi T, Amicone L, Alcalay M, Bertolini F, Testa U, Tripodi M (2012) Human haemato-endothelial precursors: cord blood CD34+ cells produce haemogenic endothelium. PLoS One 7(12):e51109. doi:10.1371/journal.pone.0051109

215. Chen T, Wang F, Wu M, Wang ZZ (2015) Development of hematopoietic stem and progenitor cells from human pluripotent stem cells. J Cell Biochem 116(7):1179-1189. doi:10.1002/jcb. 25097 